\title{
Characterization of Fate and Biological Degradation Processes Attenuating IMX-101 Munition Constituents in the Environment
}

Thomas Richard

Follow this and additional works at: https://researchrepository.wvu.edu/etd

\section{Recommended Citation}

Richard, Thomas, "Characterization of Fate and Biological Degradation Processes Attenuating IMX-101 Munition Constituents in the Environment" (2013). Graduate Theses, Dissertations, and Problem Reports. 7343.

https://researchrepository.wvu.edu/etd/7343

This Thesis is protected by copyright and/or related rights. It has been brought to you by the The Research Repository @ WVU with permission from the rights-holder(s). You are free to use this Thesis in any way that is permitted by the copyright and related rights legislation that applies to your use. For other uses you must obtain permission from the rights-holder(s) directly, unless additional rights are indicated by a Creative Commons license in the record and/ or on the work itself. This Thesis has been accepted for inclusion in WVU Graduate Theses, Dissertations, and Problem Reports collection by an authorized administrator of The Research Repository @ WVU. For more information, please contact researchrepository@mail.wvu.edu. 


\section{Characterization of Fate and Biological Degradation Processes Attenuating IMX-101 Munition Constituents in the Environment.}

Thomas Richard

Thesis submitted

to the Benjamin M. Statler College of Engineering and Mineral Resources

at West Virginia University

in partial fulfillment of the requirements for the degree of

Masters of Science in

Civil and Environmental Engineering

Jennifer Weidhaas, Ph.D., P.E., Chair

Radhey Sharma, Ph.D.

Alan Sexstone, Ph.D.

Nicole Waterland, Ph.D.

Department of Civil and Environmental Engineering

Morgantown, West Virginia

2013

Keywords: Insensitive munitions, Bioremediation, Phytoremediation, Explosives

Copyright 2013 Thomas Richard 
UMI Number: 1549776

All rights reserved

INFORMATION TO ALL USERS

The quality of this reproduction is dependent upon the quality of the copy submitted.

In the unlikely event that the author did not send a complete manuscript and there are missing pages, these will be noted. Also, if material had to be removed, a note will indicate the deletion.

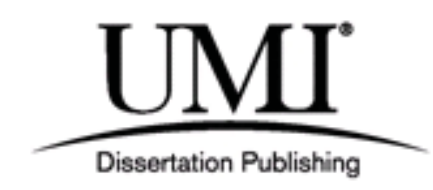

UMI 1549776

Published by ProQuest LLC (2013). Copyright in the Dissertation held by the Author.

Microform Edition (c) ProQuest LLC.

All rights reserved. This work is protected against unauthorized copying under Title 17, United States Code

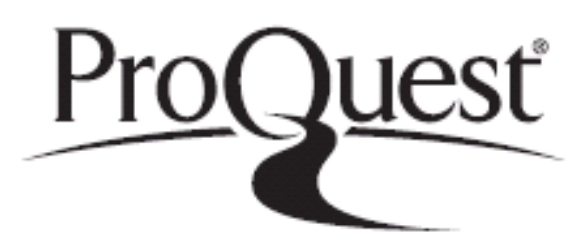

ProQuest LLC.

789 East Eisenhower Parkway

P.O. Box 1346

Ann Arbor, Ml 48106 - 1346 


\begin{abstract}
Characterization of Fate and Biological Degradation Processes Attenuating IMX-101 Munition Constituents in the Environment.

Thomas Richard
\end{abstract}

As trinitrotoluene (TNT) is replaced with insensitive munition formulations (i.e., IMX-101) that are safer to handle in military mortars, the potential release of IMX-101 munition constituents to the environment is likely to increase. IMX-101 is a composition of 2,4-dinitroanisole (DNAN), 3-nitro-1,2,4-trizole-5-one (NTO), and 1-nitroguanidine (NQ). Currently there is little data on transport and fate of DNAN and NTO in the environment. Reported herein is an evaluation of various attenuation processes that explosives are commonly subject to in the environment, specifically: 1) rainfall driven dissolution of munition fragments, 2) adsorption of dissolved munitions onto soils, 3) biological degradation of munitions, and 4) phytoremediation of munitions with various grasses. Adsorption of DNAN was observed on soils, while limited to no adsorption of NTO was observed to either soil type. Inhibition of grass stand development was seen on soils contaminated with IMX-101in concentrations exceeding $15 \mathrm{mg} \cdot \mathrm{kg}^{-1}$. Reduction in IMX-101 from at most $100 \mathrm{mg} \cdot \mathrm{kg}^{-1}$ to below detection limits (i.e., $0.1 \mathrm{mg} \cdot \mathrm{kg}^{-1}$ ) in phytoremediation plots was observed within 195 days. However, microbiological degradation of IMX-101 in soils or abiotic degradation processes were likely responsible for the majority of the IMX-101 attenuation in the phytoremediation studies based on control experiments. However, both DNAN and NQ were observed with portions of the grass roots and shoots, indicating adsorption or uptake of these compounds was occurring in the phytoremediation studies. Soil cultures enriched in liquid media were further shown capable of rapid acclimation and 
degradation of IMX-101 constituents under both aerobic and anaerobic conditions.

Biodegradation kinetics followed the Monod growth model $\left(\mu_{\max }=0.1075 \mathrm{~h}^{-1}\right.$, and $\mathrm{K}_{\mathrm{S}}=9.975 \mathrm{mg}$. $\mathrm{L}^{-1}$ ) when DNAN and NQ are provided as a sole nitrogen source with kinetic parameters similar to those reported for phenol. The findings reported herein will aid environmental engineers and military testing and training range managers estimate the fate and transport of IMX-101 in the environment and design industrial wastewater treatment systems. 


\section{Table of Contents}

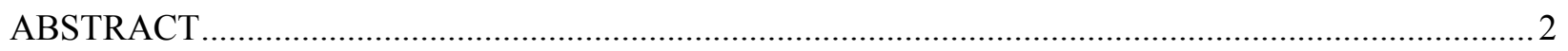

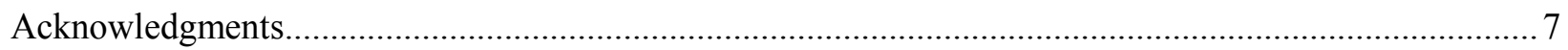

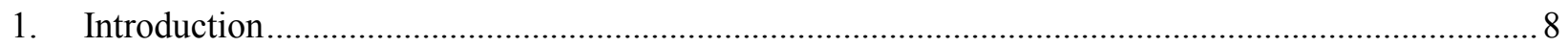

2. Bioremediation of IMX-101 munition constituents, 2,4-dinitroanisole, and 3-nitro-1,2,4-trizole-5one 9

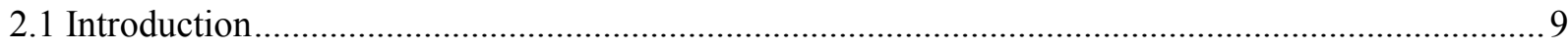

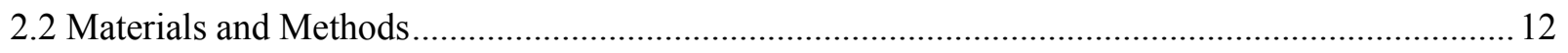

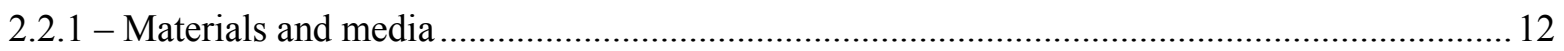

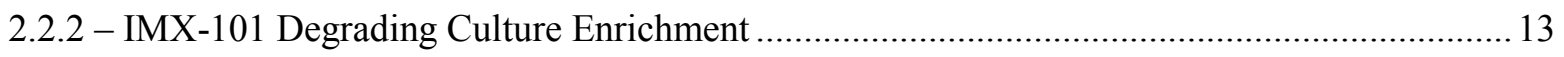

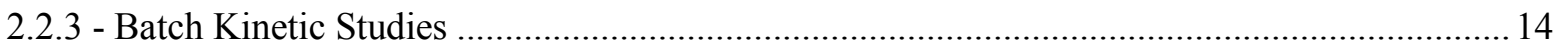

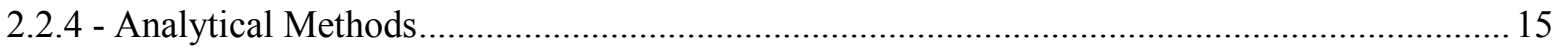

2.2.5 - IMX-101 degrading enrichment culture growth kinetics ............................................... 16

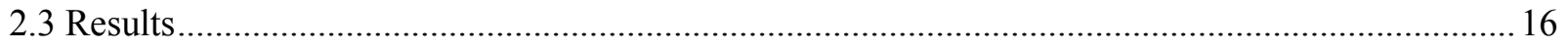

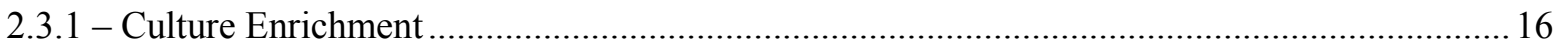

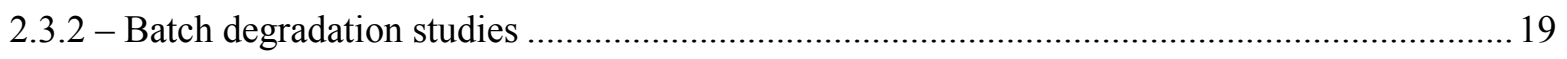

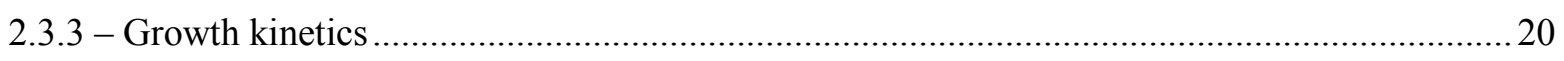

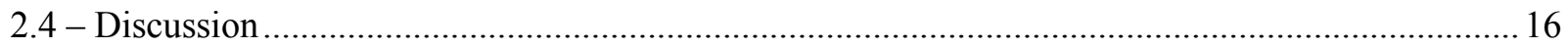

3. Dissolution, Sorption and Phytoremediation of IMX-101 constituents, 2,4-dinitroanisole, 3-nitro-

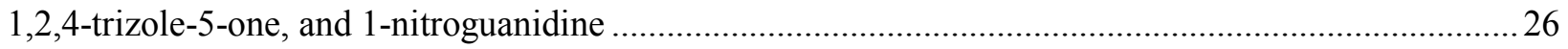

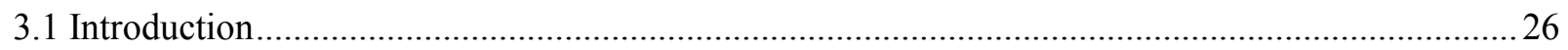




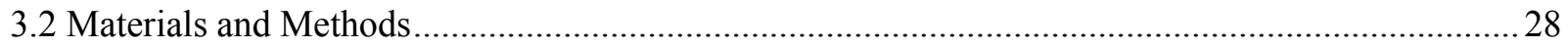

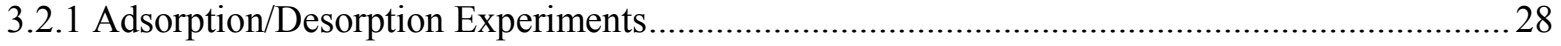

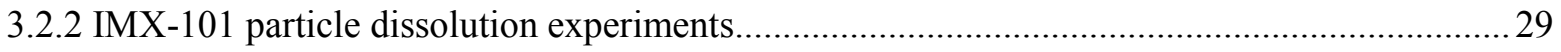

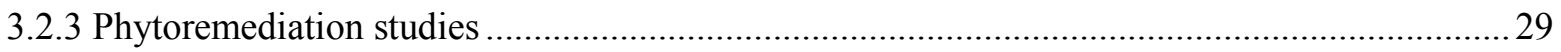

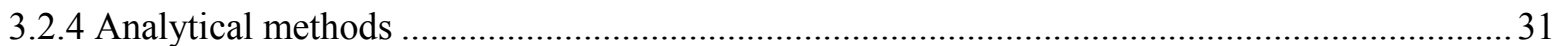

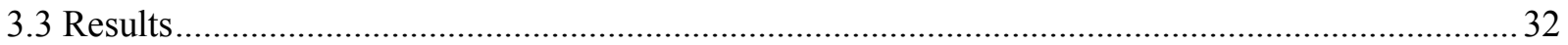

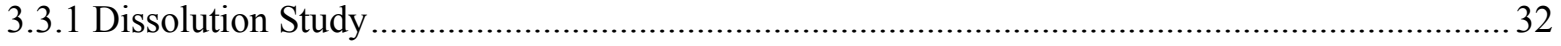

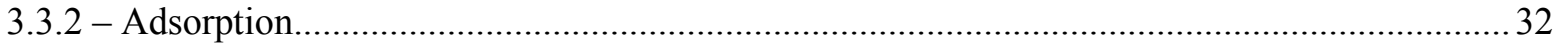

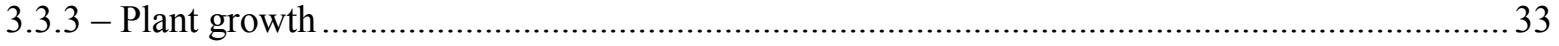

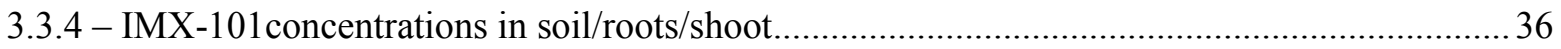

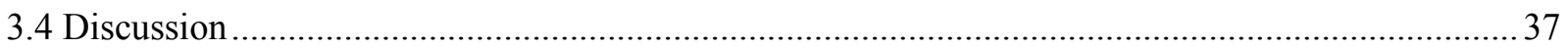

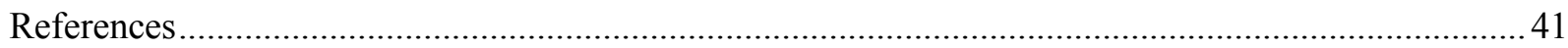

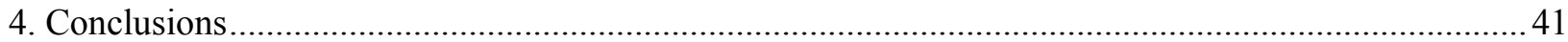




\section{Table of Figures}

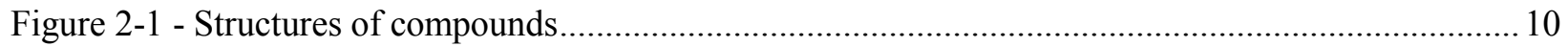

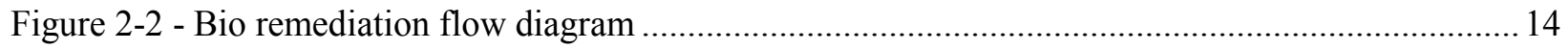

Figure 2-4 - NTO concentrations during culture enrichment........................................................ 18

Figure 2-5 - DNAN concentrations during culture enrichment......................................................... 19

Figure 2-6 - Observed and modeled enrichment culture growth on DNAN and NQ in IMX-101...........20

Figure 2-7 - Aerobic biodegradation of DNAN, NQ, and NTO at $100 \mathrm{mg} \cdot \mathrm{L}^{-1}, 50 \mathrm{mg} \cdot \mathrm{L}^{-1}, 10 \mathrm{mg} \cdot \mathrm{L}^{-1}$..

Figure 2-8 - Aerobic biodegradation of DNAN, NQ, and NTO at $15 \mathrm{mg} \cdot \mathrm{L}^{-1}$ and $25 \mathrm{mg} \cdot \mathrm{L}^{-1} \ldots \ldots \ldots \ldots \ldots . . . . .23$

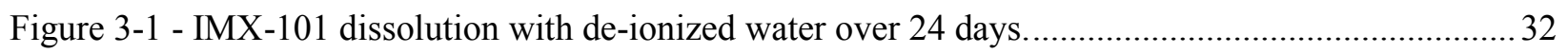

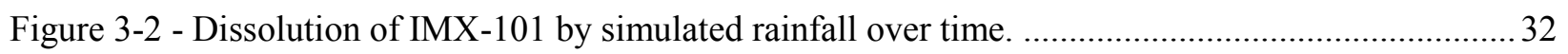

Figure 3-3 - Fractions of DNAN (ir)reversibly bound to sand, clay and organic soil $(\mathrm{n}=2) \ldots \ldots \ldots \ldots \ldots . . . .33$

Figure 3-4 - Maximum shoot and root length for each pot. …........................................................ 34

Figure 3-5 - Average root/shoot mass per shoot comparing culture vs. no culture added. ...................... 34

Figure 3-6 -DNAN, NQ and NTO concentrations in soils with plants added over time after seeding...... 35

Figure 3-7 - DNAN and NQ presence in the roots and shoots of various treatments.............................36

Figure 3-8 - Effect of IMX-101 concentrations $\left(\mathrm{mg} \cdot \mathrm{kg}^{-1}\right)$ on the growth of grasses after 195 days........36

Figure 3-9 - Estimated percent IMX-101 attenuated by different mechanisms examined in this study. .39

\section{Table of Tables}

Table 2-1 Observed and reported kinetic parameters for Monod growth models . ................................2 21

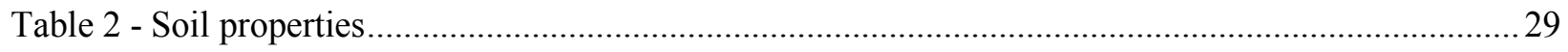

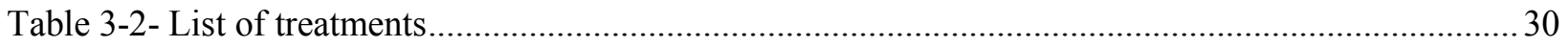




\section{Acknowledgments}

I would like to express my utmost appreciation to my advisor, Dr. Jennifer Weidhaas, for her patience, knowledge, motivation, and cheerful attitude that directed the completion this research. I would also like to thank the committee members, Dr Alan Sexstone, Dr. Nicole Waterland, and Dr. Radhey Sharma for their time and insight. I would like to thank Dr. Brian Popp in the chemistry department for access to his lab and high pressure liquid chromatography equipment. I would like to staff of the Agricultural Sciences greenhouse for allowing us permission to use a part of their greenhouse and Dr. Joseph Morton for help with microscope images. I would like to thank the CEE soils department for the usage of their sieves along with Mr. Dave Turner. I would like Pujya, Autumn, Sirisha, Xiang, Emily, and Elliot for their help with experiments and conversation in the lab. I would also like to give a special thank you to my Father, Mother and Brother who provided their support and encouragement. Lastly, I would like to thank all my friends for keeping me sane along the way. 


\section{Introduction}

New policies are now being implemented by western governments requiring defense agencies to develop safer insensitive muntions (IMs) (Davies and Provatas 2006; DeFisher et al. 2010). IMs are explosives that have been designed to resist higher levels of shock than past explosives while still maintaining military needs (Walsh et al. 2013), thus protecting military personnel. A new IM formulation, IMX-101, has been approved for use by the US Army as a replacement for TNT in certain mortars (Picatinny PA 2010). Only limited literature is currently available on the transport and fate of IMX-101 constituents, 2,4-dinitroanisole (DNAN), 3-nitro-1,2,4-trizole-5-one (NTO), 1-nitroguanidine (NQ). While NQ has been used previously in triple base propellants, DNAN and NTO have not seen significant use in explosives until the recent increase in use of IMs. It would therefore likely that DNAN and NTO will be deposited on testing and training range soils with expected IMX-101 utilization in US military mortars.

It has been shown that testing and training activities result in the deposition of explosive compounds on military test ranges in the form of unexploded ordinance and low order detonations of past explosives such as TNT, 1,3,5-Trinitroperhydro-1,3,5-triazine (RDX) and octahydro-1,3,5,7-tetranitro-1,3,5,7tetrazocine (HMX) (Pennington et al. 2001; Pennington et al. 2005). It has been estimated that in the U.S. 50 million acres exists as military test ranges (Pichtel 2012). Test ranges have resulted in unexploded ordinance and low-order detonation where incomplete detonation of explosives allows particles to remain on soil surfaces (Jenkins et al. 2001). Strategies for the treatment of explosive contaminated soils commonly include incineration, landfilling, and composting (Peterson et al. 1998). These remediation approaches can be very expensive and drastically disrupt range ecosystems. Low cost and less invasive alternatives to these methods include bioremediation and phytoremedation. Although in place treatment of explosives is limited in areas of high explosive concentrations due to inhibition of microorganisms, biological remediation strategies are ideal for low concentrations reported with explosive contamination by Unexploded ordinance (UXO) and low-order detonations (Crocker et al. 2006). The effectiveness of these strategies are dependent on the attenuation processes compounds may undergo, including 1) 
dissolution, 2) adsorption, 3) biological degradation, and 4) natural degradation processes (Best et al. 2008).

The goals of the first section of this study focused primarily on biological degradation of IMX-101 constituents and included the following:

- Enrich a microbial culture capable of degrading IMX-101 constituents.

- Evaluate the cultures ability to degrade IMX-101 constituents under aerobic conditions with limited nitrogen.

- Assess culture growth kinetics and degradation kinetics.

The goals of the second section of the study observed the major attenuation mechanisms specific to military testing and training ranges including:

- Measure the fate of IMX-101 following a simulated rainfall study and adsorption of constituents to contaminated soil.

- Determine the effect of IMX-101 on the growth of grasses.

- Determine the effects grasses and microbial cultures have on removal rates of IMX-101 in soil.

The overall objective of this study was to assess attenuation mechanisms of DNAN, NTO and to a lesser extent NQ in the environment.

\section{Bioremediation of IMX-101 munition constituents, 2,4- dinitroanisole, and 3-nitro-1,2,4-trizole-5-one}

\subsection{Introduction}

U.S. defense agencies (and other defense agencies developing similar policies) have been required by law to develop and implement safer insensitive munitions (IM) that will replace current explosives (Davies 
and Provatas, 2006; DeFisher et al., 2010). IMX-101 is an insensitive munition formulation that has been recently approved by the U.S. Army as a replacement for 2,4,6-trinitrotoluene (TNT )(Picatinny, 2010). IMX-101 contains 40 to $45 \%$ of 2,4-dinitroanisole (DNAN, $\mathrm{C}_{7} \mathrm{H}_{6} \mathrm{~N}_{2} \mathrm{O}_{5}$, CAS No. 119-27-7), 18 to $23 \%$ of 3-nitro-1,2,4-trizole-5-one (NTO, $\mathrm{C}_{2} \mathrm{H}_{2} \mathrm{~N}_{4} \mathrm{O}_{3}$, CAS No. 932-64-9), and 35 to $40 \%$ of 1-nitroguanidine (NQ, $\mathrm{CH}_{4} \mathrm{~N}_{4} \mathrm{O}_{2}$, CAS No. 556-88-7) (Samuels, 2010). US defense agencies operate an estimated 50 million acres for military training and testing exercises and some 10 million acres is expected to be contaminated from unexploded ordinance and low order detonations by explosives (Pichtel, 2012). Contamination by production and utilization is likely to increase as IMX-101 is replaced in mortars and may result in deposition of IMX-101 onto military testing and training ranges. Further the available literature on these compounds is limited compared to more widely used explosives such as TNT and RDX. Nitroguanidine has been significantly utilized as part of triple-base propellant formulations, (United States, 1989), however only recently has DNAN and NTO received increasing interest (due to developments with IM). An increased understanding of fate and transport of these compounds (Figure $2-1$ ) is therefore necessary for the development of remediation and risk management strategies.
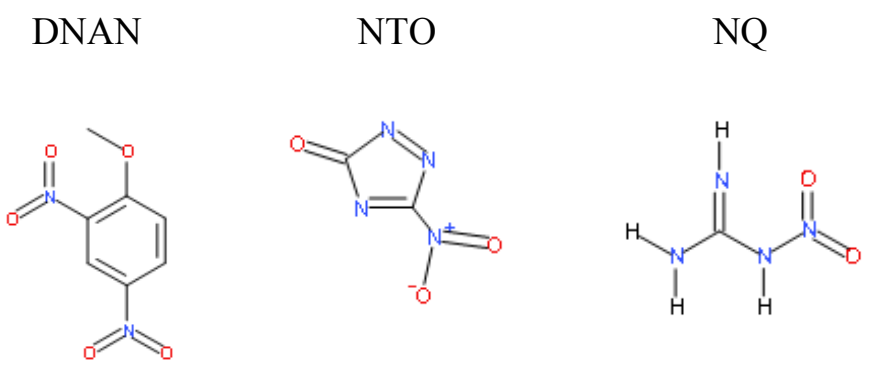

Figure 2-1 - Structures of compounds

Chemical and physical properties of compounds can potentially be used to identify their transport and fate in the environment. Both NTO and NQ are soluble in water $\left(49 \mathrm{~g} \cdot \mathrm{L}^{-1}\right.$ and $5 \mathrm{~g} \cdot \mathrm{L}^{-1}$ respectively) and have not been shown to significantly adsorb to soils (Becker, 1995; Gosch, 2012; Haag et al., 1990). DNAN is 
poorly soluble in water $\left(276 \mathrm{mg} \cdot \mathrm{L}^{-1}\right)$, producing rod shaped crystals at higher concentrations (Boddu et al., 2008). Henry's constants $\left(\mathrm{atm}-\mathrm{m}^{3} \cdot \mathrm{mol}^{-1}\right)$ for IMX-101 compounds of $5.5^{*} 10^{-4}\left(\right.$ at $\left.25^{\circ} \mathrm{C}\right)$, and $7 * 10^{-6}$ (DNAN, and NQ respectively) have been reported (Haag et al. 1990; Boddu et al. 2008) and suggest IMX volatilization losses to be insignificant. The toxicities of these compounds has been reported to be low for aquatic organisms (Schalie, 1985; Haley et al., 2009; Kennedy et al., 2013); however photolytic reductions of DNAN and NQ have resulted in the production of toxic compounds including 2,4dinitrophenol, guanidine, urea, cyanoguanidine, and nitrite (Rao et al., 2013; Burrows et al., 1988). Based on the known and expected movement of these compounds on testing and training range soils and concerns with toxicity, remediation of these compounds will likely be necessary.

The potential for biological degradation has been seen as an economical approach to remediation of contaminated sites (Lewis et al., 2004) and has been investigated previously to some extent for all three compounds in the IMX-101 formulation. NQ biodegradation has been reported under anaerobic conditions with a culture from a sewage treatment digester and was degraded from $75 \mathrm{mg} \cdot \mathrm{L}^{-1} \mathrm{NQ}$ to 0.1 $\mathrm{mg} \cdot \mathrm{L}^{-1}$ (limit of detection) over 7 days (Kaplan et al., 1982). An isolated culture of Variovorax VC1 was able to degrade NQ aerobically in soil microcosms over 6 days with glucose and succinate provided (Perreault et al., 2012a), where a total of $98.5 \%$ of the nitrogen provided by NQ was transformed to nontoxic products of $\mathrm{NH}_{4}{ }^{+}$or $\mathrm{N}_{2} \mathrm{O}$. Degradation of DNAN has been seen in anaerobic fluidized bed bioreactors with the addition of ethanol as an electron acceptor (Arnett et al., 2009; Platten III et al., 2010). Further, Arnett (2009) suggests that Levilinea sp. played an integral role in the process. Aerobic degradation of DNAN has also been shown a Bacillus sp. strain $(13 \mathrm{G})$ in soil slurries augmented with both carbon and nitrogen sources (Perreault et al., 2012b). Biotransformation of DNAN was reported under anaerobic conditions to be reduced to 2- methoxy-5-nitroaniline and 2,4-diaminoanisole (Olivares et al., 2013). Aerobic biodegradation to 5-amino-1,2,4- triazol-3-one, a structurally related compound to NTO, using Penicillium sp. and Bacillus licheniformi has been reported by Le Campion et al. (1999a). A 
total of $20 \mathrm{mg} \cdot \mathrm{L}^{-1}$ of NTO was reduced to urea by Bacillus licheniformi under aerobic conditions with NTO provided as the only nitrogen source (Le Campion et al., 1999b).

The objective of this study was to find microorganisms capable of aerobic degradation of IMX-101 constituents, DNAN, NTO, and NQ and establish if biological degradation is feasible in combination. Once established, the ability of the enrichment culture to utilize the IMX-101 compounds at varying concentrations as a sole source of nitrogen was evaluated. These batch studies were then used to determine the IMX-101 degradation kinetics and determine the culture growth kinetics.

\subsection{Materials and Methods}

\subsection{1 - Materials and Media}

The IMX-101 formulation containing 40-45\% DNAN, 18-23\% NTO, and 35-40\% NQ was provided by Picatinny Arsenal (Rockaway Township, NJ). Analytical standards for DNAN, NTO and NQ were provided by BAE Holston. Liquid minimal media used in aerobic studies contained $1800 \mathrm{mg} \cdot \mathrm{L}^{-1}$ of $\mathrm{K}_{2} \mathrm{HPO}_{4}, 600 \mathrm{mg} \cdot \mathrm{L}^{-1}$ of $\mathrm{KH}_{2} \mathrm{PO}_{4}, 200 \mathrm{mg} \cdot \mathrm{L}^{-1}$ of $\mathrm{MgSO}_{4}, 100 \mathrm{mg} \cdot \mathrm{L}^{-1}$ of $\mathrm{NaCl}, 100 \mathrm{mg} \cdot \mathrm{L}^{-1}$ of $\mathrm{KCl}, 40$ $\mathrm{mg} \cdot \mathrm{L}^{-1} \mathrm{CaCl}$. Vitamin solution was added to provide $10 \mu \mathrm{g} \cdot \mathrm{L}^{-1}$ pyridoxine $\cdot \mathrm{HCl}, 5 \mu \mathrm{g} \cdot \mathrm{L}^{-1}$ of thiamine $\cdot \mathrm{HCl}, 5 \mu \mathrm{g} \cdot \mathrm{L}^{-1}$ of riboflavin, $5 \mu \mathrm{g} \cdot \mathrm{L}^{-1}$ of calcium pantothenate, $5 \mu \mathrm{g} \cdot \mathrm{L}^{-1}$ of thioctic acid, $5 \mu \mathrm{g} \cdot \mathrm{L}^{-1}$ of p-aminobenzoic acid, $5 \mu \mathrm{g} \cdot \mathrm{L}^{-1}$ of nicotinic acid, $5 \mu \mathrm{g} \cdot \mathrm{L}^{-1}$ of vitamin $\mathrm{B} 12,2 \mu \mathrm{g} \cdot \mathrm{L}^{-1}$ of biotin, $2 \mu \mathrm{g} \cdot \mathrm{L}^{-1}$ of folic acid. Trace element solution (TES) was added to provide $2 \mathrm{mg} \cdot \mathrm{L}^{-1}$ nitrilotriacetic acid, $1 \mathrm{mg} \cdot \mathrm{L}^{-}$ ${ }^{1}$ of $\mathrm{MnSO}_{4} \cdot \mathrm{H}_{2} \mathrm{O}, 800 \mu \mathrm{g} \cdot \mathrm{L}^{-1} \mathrm{FeCl}_{3}, 200 \mu \mathrm{g} \cdot \mathrm{L}^{-1} \mathrm{CoCl}_{2} \cdot 6 \mathrm{H}_{2} \mathrm{O}, 200 \mu \mathrm{g} \cdot \mathrm{L}^{-1} \mathrm{ZnSO}_{4} \cdot 7 \mathrm{H}_{2} \mathrm{O}, 20 \mu \mathrm{g} \cdot \mathrm{L}^{-1}$ $\mathrm{CuSO}_{4} \cdot 5 \mathrm{H}_{2} \mathrm{O}, 20 \mu \mathrm{g} \cdot \mathrm{L}^{-1} \mathrm{NiSO}_{4} \cdot 6 \mathrm{H}_{2} \mathrm{O}, 20 \mu \mathrm{g} \cdot \mathrm{L}^{-1} \mathrm{Na}_{2} \mathrm{MoO}_{4} \cdot 2 \mathrm{H}_{2} \mathrm{O}, 20 \mu \mathrm{g} \cdot \mathrm{L}^{-1} \mathrm{Na}_{2} \mathrm{SeO}_{4}, 20 \mu \mathrm{g} \cdot \mathrm{L}^{-1}$ $\mathrm{Na}_{2} \mathrm{WO}_{4}, 8 \mu \mathrm{g} \cdot \mathrm{L}^{-1} \mathrm{H}_{3} \mathrm{BO}_{3}$. Media recipes were modified from Hurst and Crawford (2007). Chemicals were purchased from Fisher Scientific (Hampton, NH) excluding $\mathrm{K}_{2} \mathrm{HPO}_{4}$ (Sigma-Life Science, St. Louis MO), glucose, nitrilotriacetic acid, $\mathrm{Na}_{2} \mathrm{MoO}_{4} \cdot 2 \mathrm{H}_{2} \mathrm{O}, \mathrm{Na}_{2} \mathrm{SeO}_{4}, \mathrm{Na}_{2} \mathrm{WO}_{4}$ (Acros Organics, Geel, Belgium) and vitamin and $\mathrm{NiSO}_{4} \cdot 6 \mathrm{H}_{2} \mathrm{O}$ (Alfa Aesar, Ward Hill, MA). TES chemicals were purchased from (Acros Organics, Geel, Belgium) excluding Thioctic, vitamin B12 (MP Biomedical, Solon, Ohio) and folic acid (Fisher Scientific, Hampton, NH, 95\%). Purities were $>98 \%$ unless noted otherwise. An Orion ROSS pH 
electrode (ThermoScientific, Waltham, MA) was used to measure solution $\mathrm{pH}$, which was maintained between 7-7.5. Carbon (C) was provided as $500 \mathrm{mg} \cdot \mathrm{L}^{-1}$ of each of the following: fructose, sodium lactate, and glucose; nitrogen $(\mathrm{N})$ was provided as $100 \mathrm{mg} \cdot \mathrm{L}^{-1}$ of both $\mathrm{KNO}_{3}$ and $\mathrm{NH}_{4} \mathrm{Cl}$; yeast extract (YE) was added to a concentration of $100 \mathrm{mg} \cdot \mathrm{L}^{-1}$. Carbon and nitrogen sources were provided to ensure microorganisms growth was not limited by $\mathrm{C} / \mathrm{N}$ availability. When IMX-101 compounds served as the sole nitrogen source, $\mathrm{N}$ available from the vitamin solution was less than $0.06 \mathrm{mg} \cdot \mathrm{L}^{-1}$.

Aerobic cultures were grown in $250 \mathrm{~mL}$ Wheaton media bottles with $75 \mathrm{~mL}$ of minimal media and capped with sterile foam stoppers. Anaerobic cultures were inoculated into sterilized amber VOA vials containing $30 \mathrm{~mL}$ of minimal media solution described above with a five-fold increase in TES compared to aerobic cultures. VOA vials were sparged with compressed nitrogen (Airgas, Radnor Township, PA, $99 \%$ purity) to remove oxygen from the headspace. All cultures were incubated in the dark at $25^{\circ} \mathrm{C}$ on a shaker table at $150 \mathrm{rpm}$.

\subsection{2 - IMX-101 Degrading Culture Enrichment}

Feed stocks were selected to ensure the enrichment of a culture capable of degrading IMX-101 constituents and included: activated sludge, anaerobically digested sludge, soil, and compost. Activated sludge and sludge from an anaerobic digester were collected from a nearby wastewater treatment plant (Star City, WV). Residential food and yard waste compost was added to water and mixed into a slurry. Soil microorganisms were enriched from a soil that had previously been exposed to IMX-101 for 110 days in the lab. Each treatment was provided with $25 \mathrm{mg} \cdot \mathrm{L}^{-1} \mathrm{IMX}-101$. Microcosms were inoculated using $100 \mu \mathrm{L}$ of each of the slurry feed stocks (i.e. all but soil) and added to microcosms with $\mathrm{C}, \mathrm{N}$ and YE, at concentrations as described in section 2.1. One gram of soil was added to microcosms as follows: (Treatment i) $\mathrm{C}$, (Treatment ii) N, (Treatment iii) $\mathrm{C}+\mathrm{N}$, (Treatment iv) $\mathrm{C}+\mathrm{N}+$ YE. Hereafter, treatment i will be referred to as "i," etc. Activated sludge, compost slurry and soil cultures were grown aerobically, while anaerobic cultures were inoculated with digested sludge. 
Treatments were incubated for nine days and then re-spiked with IMX-101, targeting $25 \mathrm{mg} \cdot \mathrm{L}^{-1}$. At each sample point $2 \mathrm{~mL}$ aliquots were removed from each treatment and syringe filtered through a nylon 0.45 $\mu \mathrm{m}$ filter (FisherBrand, Waltham, MA) into amber vials and stored at $4{ }^{\circ} \mathrm{C}$ until high pressure liquid chromatography by photo diode array (HPLC-PDA) or ultra-pressure liquid chromatography by tandem mass spectrometry (UPLC-MS/MS) analysis. Samples were taken before and after the re-spiking of IMX101, and following a week after IMX-101 re-addition. At the end of the first week $100 \mathrm{~mL}$ of each enriched culture was transferred into a bottle with the same initial conditions and incubated for a week. These were analyzed for IMX-101 compounds and cell biomass at the start and end of their week incubation.

\subsection{3 - Batch Kinetic Studies}

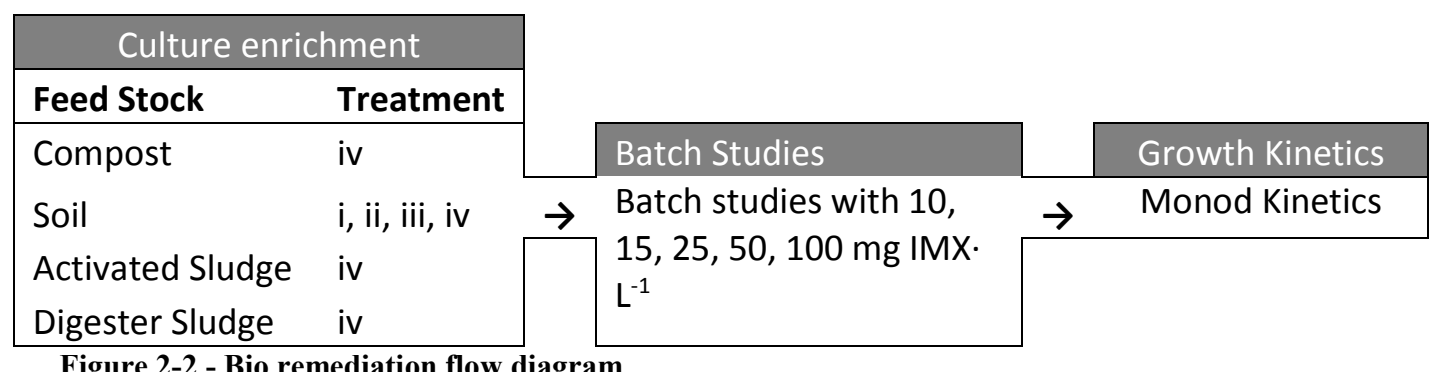

Figure 2-2 - Bio remediation flow diagram

The soil culture from treatment $\mathrm{i}$ was selected to be used in aerobic batch kinetic studies based on observed degradation and growth. A flow diagram of the enrichment and kinetic studies is provided in Figure 2-2. The culture was added to treatments with varying concentrations of IMX-101 $(10,15,25,50$, and $100 \mathrm{mg} \cdot \mathrm{L}^{-1}$ ) and destructively sampled at 10 different time points over 10 days. The treatment $\mathrm{i}$ culture was maintained and used to inoculate the $10 \mathrm{mg} \cdot \mathrm{L}^{-1}$ and $25 \mathrm{mg} \cdot \mathrm{L}^{-1}$ treatments. The culture was stored in sterile $50 \%$ glycerol at $-20{ }^{\circ} \mathrm{C}$, prior to inoculation of the 15,50 and $100 \mathrm{mg} \cdot \mathrm{L}^{-1}$ at a later date. Sample microcosms were prepared following the aerobic method described in section 2.2.2 and were inoculated with $100 \mu \mathrm{L}$ of the maintained culture. An abiotic control containing $300 \mathrm{mg} \cdot \mathrm{L}^{-1}$ of sodium azide was included to inhibit microorganism respiration. Single samples were taken daily in duplicate 
from separate microcosms. Samples were analyzed for IMX-101 constituents by HPLC or UPLC-MS/MS analysis along with cell dry weight measurements.

\subsection{4 - Analytical Methods}

Cell growth during culture enrichment experiments was determined by optical density measurements. However, the formation of biofilms and their inconsistent suspension made the measurements unreliable. Instead, cell dry weight measurements were determined following standard methods 2540D (Hurst and Crawford 2007). A $25 \mathrm{~mL}$ sample was filtered through a $0.45 \mu \mathrm{m}$ mixed cellulose filter (FisherBrand, Waltham, MA) and evaporated to dryness at $104{ }^{\circ} \mathrm{C}$ for one hour. The difference in weight collected on the filter was used to determine the cell dry weight.

DNAN was analyzed by HPLC-PDA throughout these studies and NQ was analyzed UPLC-MS-MS. NTO was analyzed by HPLC for enrichment studies and the UPLC method was used during batch kinetic studies. A Shimzadzu HPLC system was run using an Adsorbosphere C-18 column (Alltech, Deerfield, IL, 250mm x 4.6mm, $5 \mu \mathrm{m}$ particle size). Absorbance was measured using a photo diode array (PDA) detector. Runs were isocratic with a $1 \mathrm{~mL} \cdot \mathrm{min}^{-1}$ flow rate. DNAN used a mobile phase of $40 \%$ acetonitrile and $60 \%$ water with an injection volume of $40 \mathrm{uL}$. Absorbance was measured at $296 \mathrm{~nm}$ and DNAN eluted at 8 min. NTO separation was accomplished using a mobile phase of $98 \%$ water, $1 \%$ acetonitrile and $1 \%$ trifluoroacetic acid (Sigma-Aldrich, St. Louis, MO, HPLC grade) and $100 \mathrm{uL}$ sample injections. NTO was measured at $315 \mathrm{~nm}$, elution time was found to be at $4 \mathrm{~min}$. Acetonitrile for usage with HPLC analysis was purchased from EMD Millipore (Billerica, MA, 99.8\% purity) and water was purified by a Nanopure Infinity system (Barnstead, Dubuque, IA, 18 $\Omega$ ).

Measurement by UPLC-MS-MS was conducted on a ThermoScientific Accela system attached to a quadrapole mass detector and orbitrap analyzer (QExactive, ThermoScientific, Waltham, MA). A heated electrospray ion source (HESI) was operated in negative mode. The resolution was set to 70,000 FWHM and scanned from 50 to $750 \mathrm{~m} / \mathrm{z}$. Spray voltage was $3.5 \mathrm{kV}$, capillary temperature was $300{ }^{\circ} \mathrm{C}$, heater temperature $310^{\circ} \mathrm{C}$. A total of $10 \mu \mathrm{L}$ of sample was injected into a Hypersil Gold column $(50 \mathrm{~mm} \times 2.1$ 
$\mathrm{mm}, 1.9 \mu \mathrm{m}$ particle size, ThermoScientific, Waltham, MA) with a flow rate of $200 \mu \mathrm{L} \cdot \mathrm{min}^{-1}$. Mass to charge ratios $(\mathrm{m} / \mathrm{z})$ that were used to analyze for NTO and NQ were 103.0248 and $129.0041 \mathrm{~m} / \mathrm{z}$, respectively. An isocratic gradient was used with a mobile phase of 60:40 methanol-water with $1 \mathrm{mM}$ of ammonium acetate (HPLC grade). Reagents were LCMS grade and purchased from Fisher Scientific (Waltham, MA).

\subsection{5 - IMX-101 degrading enrichment culture growth kinetics}

Batch growth kinetics of the IMX-101 degrading enrichment culture were modeled using the Monod model (Haldane 1965). The Monod equation is an empirical based model where growth is based only on limiting substrate shown in Eq. 1 (Haldane 1965).

$$
\mu=\frac{\mu_{\max } S}{\mathrm{~K}_{\mathrm{S}}+S}
$$

Where, $\mu$ is the specific growth rate $\left(h^{-1}\right), \mu_{\max }$ is the maximum growth rate $\left(h^{-1}\right), K_{S}$ is the half saturation constant $\left(\mathrm{mg} \cdot \mathrm{L}^{-1}\right)$, and $\mathrm{S}$ is the substrate concentration $\left(\mathrm{mg} \cdot \mathrm{L}^{-1}\right)$. Nonlinear regressions were calculated using SigmaPlot 11® (Systat Software Inc., San Jose, CA) software.

\subsection{Results}

\subsection{1 - Culture Enrichment}

DNAN concentrations in the enrichment cultures fed IMX-101 over the two week period are presented in Figure 2-3A for the four different source of innocula and in Figure 2-3B for the follow on soil enrichment cultures. As shown in Figure 2-3A after nine days of incubation there was no detection of DNAN in the $\mathrm{C}, \mathrm{N}$ and $\mathrm{YE}$ treatments (i.e., treatment iv) in cultures originating from compost, soil or digested sludge. Less degradation was seen in the activated sludge culture (i.e., 80\%) compared to the other treatments (Figure 2-3A). Follow on studies were conducted on soil treatments as evidence by optical density measurements (data not shown). As shown in Figure 2-3B for the follow on soil treatments, where $\mathrm{C} / \mathrm{N} / \mathrm{YE}$ additions were varied, degradation was seen only where carbon was provided (i.e., IMX-101 constituents served as the sole source of nitrogen). In the eight day period following the IMX-101 
addition, negligible removal of DNAN was observed in aerobic treatments, while complete degradation was observed in anaerobic cultures (Figure 2-3B). After re-seeding the cultures in fresh media, DNAN degradation studies were repeated and an increase in removal (up to 90\%) in the activated sludge treatment was observed (not shown). Figure 2-4

NTO concentrations in the enrichment cultures fed IMX-101 over the two week period are presented in Figure 2-4A for the three different source of innocula and in Figure 2-4B for the follow on soil enrichment cultures. Complete NTO degradation was only seen in anaerobic treatments where $\mathrm{C}+\mathrm{N}+\mathrm{YE}$ (treatment iv) was provided (Figure 2-4). Significant but incomplete removal of NTO was also seen in compost with C, N, and YE added (65\%, Figure 2-3A) and soil with carbon added (90\%, Figure 2-3B). The anaerobic culture was also the only treatment to show complete degradation 1 week following IMX101 re-addition. The transfer of cultures into new microcosms (same initial media conditions) increased degradation in treatments where $\mathrm{C}, \mathrm{N}$ and $\mathrm{YE}$ were provided, but removal decreased in treatments when only $\mathrm{C}$ and/or $\mathrm{N}$ was provided. NQ was not measured during culture enrichment experiments. 

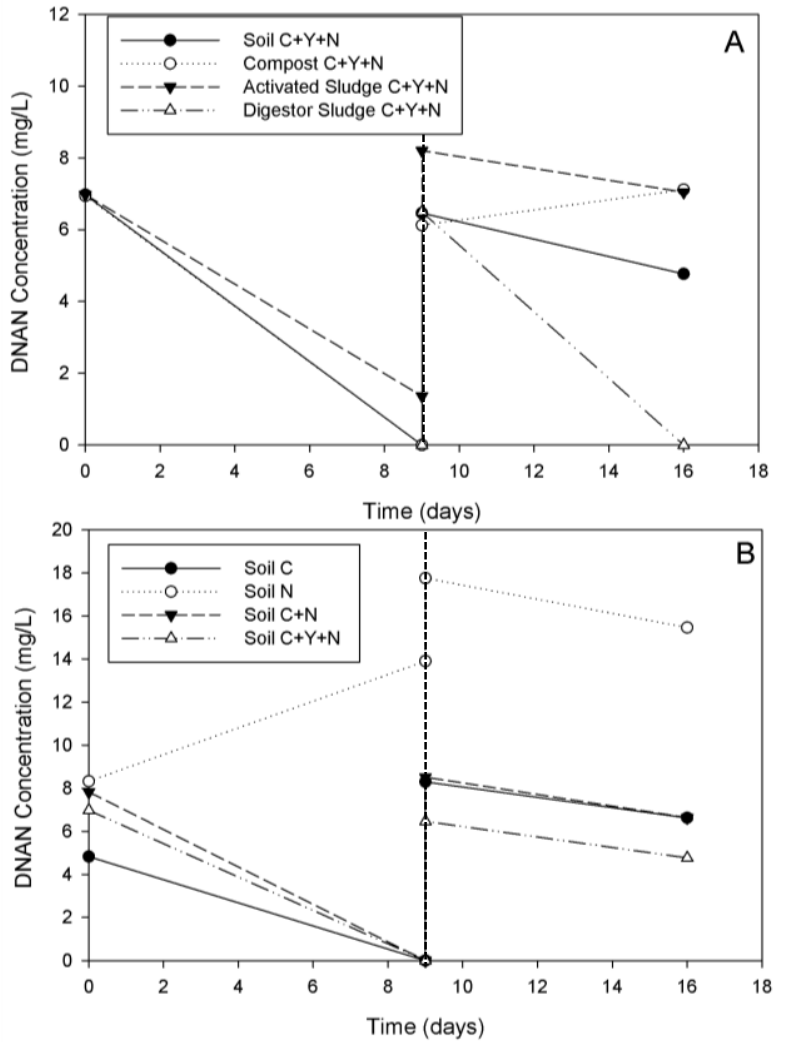

Figure 2-3 - NTO concentrations during culture enrichment (A) in treatments of $\mathrm{C}, \mathrm{N}$ and $\mathrm{YE}$ with the different feed stocks used and (B) follow on studies with $i$, ii, iii, iv treatments. The treatment was re-spiked after nine days with $25 \mathrm{mg}$ IMX $\cdot \mathrm{L}^{-1}$, shown by the vertical dashed line. Digester sludge was grown under anaerobic conditions, all other treatments were aerobic. 

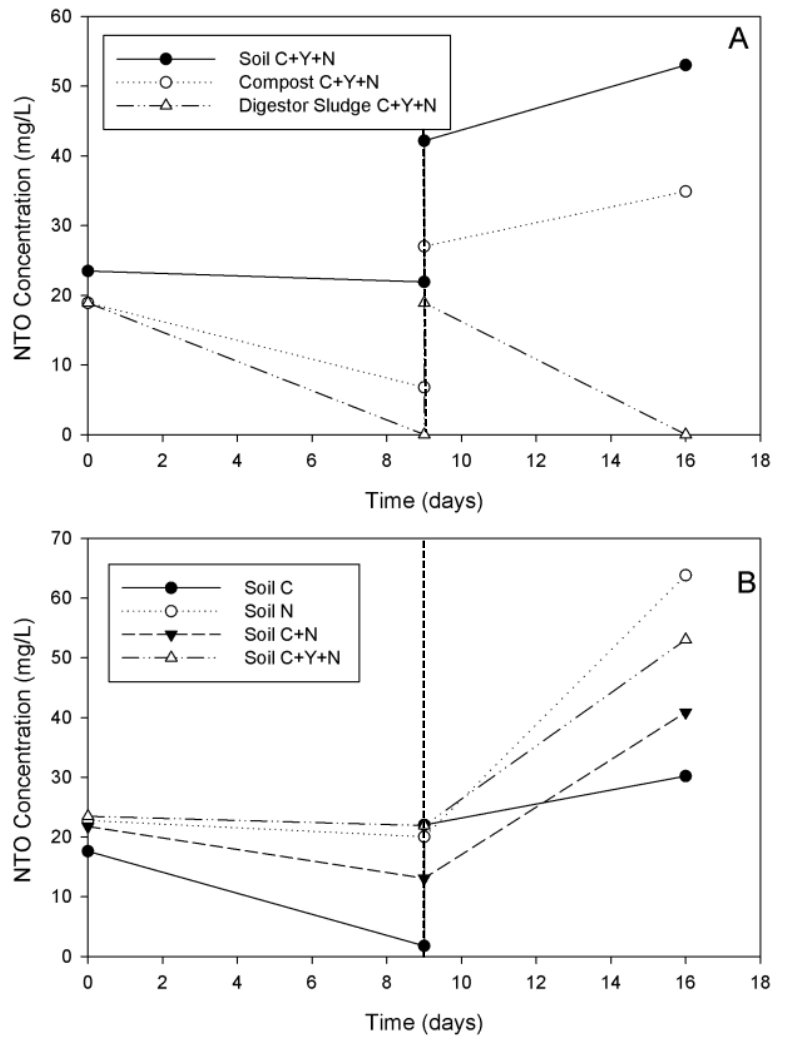

Figure 2-4 - DNAN concentrations during culture enrichment (A) in treatments of $C, N$ and $Y E$ with the different feed stocks used and (B) follow on studies with $i$, ii, iii, iv treatments. The treatment was re-spiked after nine days with $25 \mathrm{mg} I M X \cdot L^{-1}$, shown by the vertical dashed line.Digester sludge was grown under anaerobic conditions, all other treatments were aerobic.

\subsection{2 - Batch degradation studies}

The soil + carbon (treatment i) enrichment culture was selected for further study due to its favorable growth rates on IMX-101 as evidence by optical density measurements (data not shown) and on observed degradation of both DNAN and NTO in follow on enrichment studies. Batch degradation studies were conducted on the enrichment culture obtained from the soil + carbon treatments. Nitrogen provided in the media was limited to IMX-101 compounds. Nitrogen provided by the vitamin solution was negligible and determined to account for less than $1 \mathrm{mg} \cdot \mathrm{L}^{-1}$ of biomass (based on a mass balance with $\mathrm{C}_{5} \mathrm{H}_{7} \mathrm{NO}_{2}$ ).

Generally, the order of degradation of the IMX-101 constituents was 1) DNAN, 2) NQ and 3) NTO. In all cases, regardless of initial IMX-101 concentration, NQ degradation was delayed for approximately 24-48 
hours after inoculation. Rapid degradation was seen to the limit of detection in 24 hours following the lag phase in each of the concentrations tested (Figure 2-6 and Figure 2-7). NTO degradation was also seen to follow a delay in degradation similar the initial NQ removal rates. However, rapid degradation of NTO occurred only in the $50 \mathrm{mg} \cdot \mathrm{L}^{-1}$ treatment. Generally, NTO degradation rates were slower than NQ and DNAN in the 15,25 and $100 \mathrm{mg} \cdot \mathrm{L}^{-1}$ treatments. No degradation of NTO was observed in the $10 \mathrm{mg} \cdot \mathrm{L}^{-1}$ IMX-101 treatment over the 10 day period. DNAN degradation began at start of the experiment and was reduced to the limit of detection within 48 hours in the 10,50 and $100 \mathrm{mg} \cdot \mathrm{L}^{-1}$ treatments. However, removal of DNAN in the 15 and $25 \mathrm{mg} \cdot \mathrm{L}^{-1}$ treatments was seen after an extended 140 to 190 hours of incubation (Figure 2-7). Abiotic degradation seen in inhibited growth controls illustrate that there may be possible abiotic degradation processes, however these cannot account any more than $30 \%$ removal for any one case (Figure 2-6 and Figure 2-7).

\subsection{3 - Growth kinetics}

The specific growth rates are plotted in relation to the concentration of DNAN and NQ along with the predicted Monod curve are in Figure 2-5. NTO degradation occurred after exponential phase of growth, therefore it was not factored into the calculation of substrate concentration (i.e., $\mathrm{S}$ in the models included DNAN and NQ only). Values for $\mu_{\max }$, and $\mathrm{K}_{\mathrm{S}}$, are also reported in Table 2-1. Standard error of estimate for the model was 0.0182 , R-squared was .7471, and the $\mathrm{P}$ value was $\mathrm{P}=0.0013$.

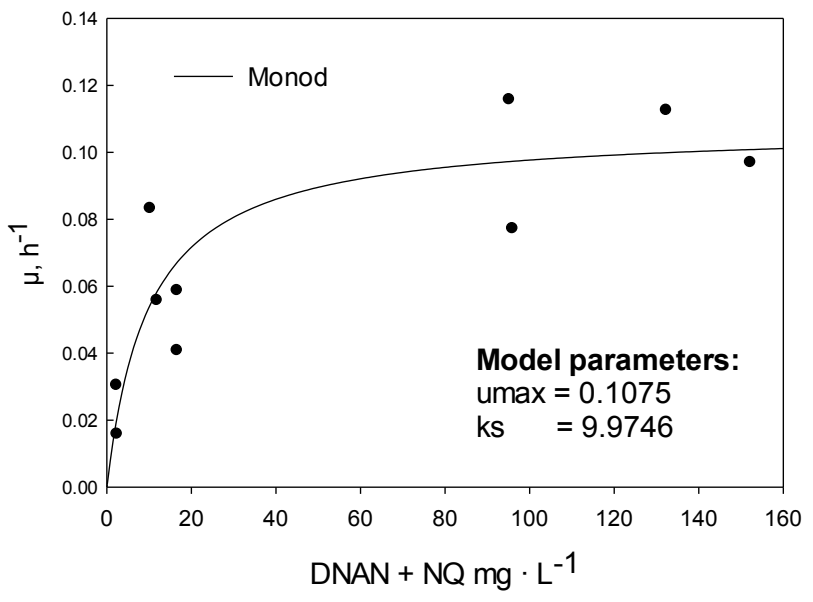

Figure 2-5 - Observed and modeled enrichment culture growth on DNAN and NQ in IMX-101. 
Table 2-1 Observed and reported kinetic parameters for Monod growth models with various substrates and cultures.

\begin{tabular}{|l|c|c|c|l|l|l|}
\hline Compound & $\mu_{\max }\left(\mathrm{h}^{-1}\right)$ & $\begin{array}{c}\mathrm{K}_{\mathrm{s}} \\
\left(\mathrm{mg} \cdot \mathrm{L}^{-1}\right)\end{array}$ & $\begin{array}{c}\text { Temp. } \\
\left({ }^{\circ} \mathrm{C}\right)\end{array}$ & \multicolumn{1}{|c|}{ Inocula } & \multicolumn{1}{c|}{ Conditions } & Reference \\
\hline $\begin{array}{l}\text { DNAN } \\
\text { and NQ }\end{array}$ & 0.1075 & 9.975 & 30 & Mixed & $\begin{array}{l}\text { Aerobic, } \\
\text { minimal media } \\
\text { with carbon } \\
\text { addition }\end{array}$ & This study \\
\hline Phenol & 0.44 & 6.19 & 26 & $\begin{array}{l}\text { fluoroescens } \\
2218\end{array}$ & $\begin{array}{l}\text { Aerobic, } \\
\text { minimal media } \\
\text { with nitrogen } \\
\text { addition }\end{array}$ & $\begin{array}{l}\text { (Kumaran } \\
\text { and } \\
\text { Paruchuri } \\
\text { 1997) }\end{array}$ \\
\hline RDX & $1.53 \pm 0.06$ & $50 \pm 0.007$ & ND & Mixed & $\begin{array}{l}\text { Aerobic, } \\
\text { minimal media }\end{array}$ & $\begin{array}{l}\text { (Young et } \\
\text { al. 1997) }\end{array}$ \\
\hline RDX & $0.66 \pm 0.07$ & $40 \pm 0.02$ & ND & S. marcescens & $\begin{array}{l}\text { Aerobic, } \\
\text { minimal media }\end{array}$ & $\begin{array}{l}\text { (Young et } \\
\text { al. 1997) }\end{array}$ \\
\hline
\end{tabular}

$\mathrm{ND}=$ data not reported 

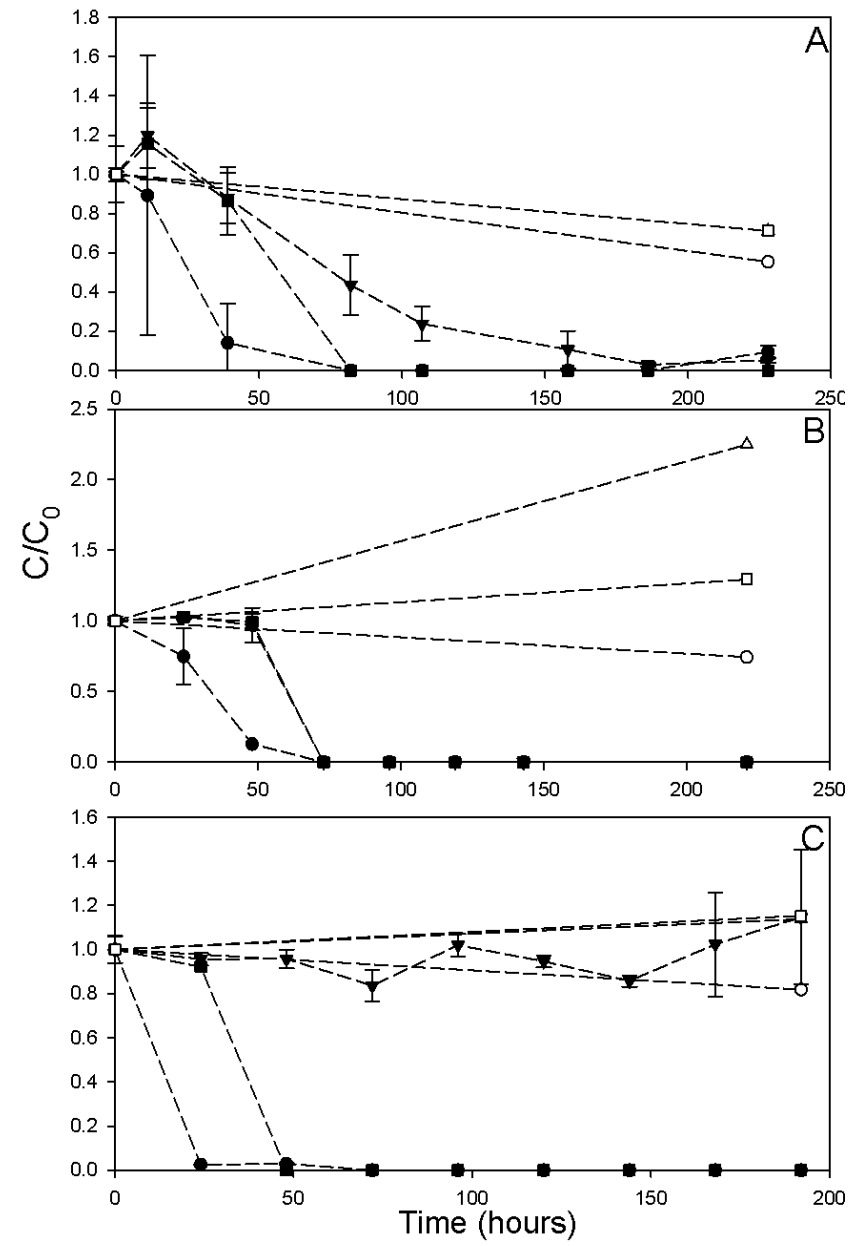

Figure 2-6 - Aerobic biodegradation of DNAN (•), DNAN control (O), NQ (घ), NQ control ( $\square)$, NTO ( $\nabla)$, and NTO control $(\triangle)$ at different IMX-101 concentrations including $100 \mathrm{mg} \cdot \mathrm{L}^{-1}(\mathrm{~A}), 50 \mathrm{mg} \cdot \mathrm{L}^{-1}(B)$, and $10 \mathrm{mg} \cdot \mathrm{L}^{-1}(C)$. Average and standard deviation of duplicate microcosms are shown $(n=2)$. 


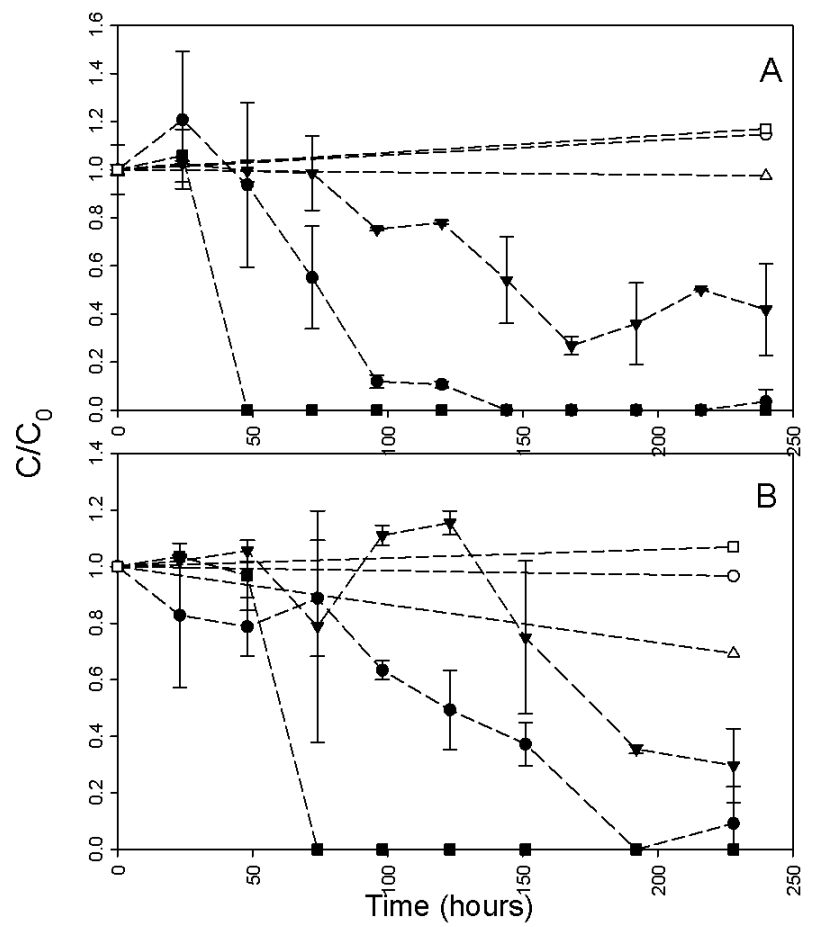

Figure 2-7 - Aerobic biodegradation of DNAN (•), DNAN control (O), NQ ( $\square)$, NQ control ( $\square)$, NTO ( $)$ ), and NTO control $(\triangle)$ at different IMX-101 concentrations of $15 \mathrm{mg}$. $\mathrm{L}^{-1}(\mathrm{~A}), 25 \mathrm{mg} \cdot \mathrm{L}^{-1}(\mathrm{~B})$. Points are average of two values. Error bars represent the standard deviation $(n=2)$. 


\section{4 - Discussion}

The broad diversity of microorganisms reported in the literature to degrade IMX-101 compounds (Perreault et al. 2012; Perreault et al. 2012; Arnett et al. 2009; Kaplan et al. 1982; Le Campion et al. 1999; Olivares et al. 2013) along with rapid acclimation of cultures observed in this study, suggest IMX101 biodegradation may readily occur in natural and engineered treatments systems. The reduced degradation of IXM-101 constituents in aerobic cultures following the IMX-101 re-spike may have resulted from reduction in available oxygen. However, it is possible that build-up of inhibitory byproducts may have resulted in the reduced removal of DNAN and NTO in aerobic treatments. It may therefore be necessary to identify and characterize possible by-products to assess: the potential of aerobic treatment; and to determine if increased toxicity occurs as a result of degradation. Anaerobically grown cultures completely removed DNAN and NTO both before and after the re-spike of IMX-101, and suggest anaerobic treatment as an effective strategy for the treatment of explosives wastes. Treatment designs may also need to account for delayed degradation onsets seen with NTO and NQ; although NQ could also be delayed by preferential utilization of DNAN by the enrichment culture in these studies.

Unlike DNAN and NQ, aerobic NTO removal was insignificant in initial culturing experiments and occurred at a slower rate, especially at lower concentrations. This, in combination with the lag phase in observed degradation, may suggest that NTO requires a much longer acclimation period to enhance removal rates of NTO. It may also suggest a certain concentration must be present for organisms to degrade NTO.

Degradation of DNAN and NQ during the exponential phase of microbial growth may suggest that these compounds were utilized as nitrogen sources due to the limited presence of nitrogen in the media.

Previous studies have reported aerobic mineralization of $\mathrm{NQ}$ to $\mathrm{NH}_{3}$ compounds as well as $\mathrm{N}_{2} \mathrm{O}$ by abiotic and biotic reduction pathways to nitrourea (Perreault et al. 2012). The complete reduction would net two $\mathrm{NH}_{3}$ per NQ compound, which could be used as a nitrogen source. The delayed onset of NQ degradation may indicate the utilization of DNAN as a source nitrogen source. However, Perreault et al. (2012) and 
Olivares et al. (2013) do not suggest the release of nitrogen in their proposed degradation pathways. It is therefore possible that an alternative degradation pathway for DNAN exists where cleavage of the ortho and/or para nitro groups occurs. The possible products that could result are 1-methoxy-4-nitro-benzene (ortho group cleavage), 1-methoxy-2-nitro-benzene (para group cleavage), or anisole (both).

Growth kinetics based on degradation of NQ and DNAN suggest that slower growth may be expected in comparison to growth rates seen with RDX and phenol. Additionally the data collected in this study suggest that inhibition of bacterial growth occurs at higher IMX-101 concentrations. These values may be beneficial for designing of facilities to treat IMX-101 containing waste. This study has also shown that IMX-101 constituents can serve as the sole nitrogen source for an enrichment culture. Additional studies may need to be conducted to further assess degradation IMX-101 compounds separately to rule out or confirm co-metabolic process or cooperative interactions that exist between compounds. Based on these studies it can be expected that biotransformation of these compounds will occur in the environment under conditions reported in this manuscript. 


\section{Dissolution, Sorption and Phytoremediation of IMX-101 constituents, 2,4-dinitroanisole, 3-nitro-1,2,4-trizole-5-one, and 1- nitroguanidine}

\subsection{Introduction}

U.S. and other western countries are developing policy to ensure the development and implementation of safer insensitive munitions (IM) to replace current explosives (Davies and Provatas, 2006; DeFisher et al., 2010). IMs are explosives designed to be less sensitive to sympathetic detonation while remaining as effective as past explosives. The US Army has recently approved IMX-101, an IM formulation, as a replacement for TNT (Picatinny, 2010). IMX-101 is estimated to be approximately 40 to $45 \%$ of 2,4dinitroanisole (DNAN, C7H6N2O5, CAS No. 119-27-7), 18 to 23\% of 3-nitro-1,2,4-trizole-5-one (NTO, C2H2N4O3,CAS No. 932-64-9), and 35 to 40\% of 1-nitroguanidine (NQ, CH4N4O2, CAS No. 556-887)(Samuels, 2010). NQ fate, transport and treatment has been the subject of investigation in the past, due to its usage in triple-propellants (United States, 1989). However, DNAN and NTO have not been as widely utilized and are less understood in terms of fate and transport.

The occurrence of unexploded ordinance (UXO), low-order detonation and high explosive residues has been reported on training ranges (Jenkins et al., 2001). Following deposition onto range soils, mechanisms for ordinance attenuation include dissolution into water, adsorption onto soil, and natural degradation/removal processes (i.e. photodegradation, plant uptake, and biodegradation) (Best et al. 2008). This understanding of munition compound attenuation will both aid in determining their expected fate and transport for the development of remediation strategies.

Reported characteristics of chemicals can be used to aid in determining expected munitions fate in the environment. Solubilities of DNAN, NTO, and NQ are $276 \mathrm{mg} \cdot \mathrm{L}^{-1}, 49 \mathrm{~g} \cdot \mathrm{L}^{-1}$ and $5 \mathrm{~g} \cdot \mathrm{L}^{-1}$, respectively, suggesting only NTO and NQ will readily dissolve into water (Haag et al., 1990; Becker, 1995; Boddu et 
al., 2008). Adsorption of NQ to soils and sediments has been reported (Gosch, 2012; Haag et al., 1990). DNAN adsorption has been studied using granular activated carbon (Boddu et al., 2009) as well as alkali and organosolv lignin's (Saad et al. 2012); however no studies have evaluated the potential of DNAN adsorption to soils. Henry's constants $\left(\mathrm{atm}-\mathrm{m}^{3} / \mathrm{mol}\right)$ of $5.5^{*} 10^{-4}$ (at $\left.25^{\circ} \mathrm{C}\right)$, and $7 * 10^{-6}\left(\right.$ at $\left.25^{\circ} \mathrm{C}\right)$ have been reported for DNAN and NQ, respectively (Haag et al., 1990; Boddu et al., 2008) suggesting these IMX-101 compounds are non-volatile.

The release of these compounds into the environment may result in natural degradation processes such as photodegradation and biological degradation. Photodegradation of IMX-101 compounds has been reported for both DNAN and NQ (Rao et al., 2013; Burrows et al., 1988), however both resulted in more toxic by-products (2,4-dinitrophenol, guanidine, urea, cyanoguanidine, and nitrite) . UV photodegradation of NTO was observed to only occur with the inclusion of $\mathrm{TiO}_{2}$ as a catalyst (Le Campion et al., 1999c). Photodegradation is unlikely to be a significant attenuation mechanism for subsurface contamination.

Biological degradation has been previously reported for each IMX-101 compound in only a few studies. Aerobic and anaerobic degradation of NQ has been observed using soil microorganisms and digested sewage sludge as the treatment inoculant (Perreault et al., 2012a; Kaplan et al., 1982). Another study conducted by Perreault et al. (2012b) showed biotransformation of DNAN under aerobic conditions in soil slurries with carbon and nitrogen provided. Anaerobic degradation of DNAN was shown to be reduced to 2- methoxy-5-nitroaniline and 2,4-diaminoanisole (Olivares et al., 2013). NTO was seen to degrade to urea under aerobic conditions when provided as the sole nitrogen source by Bacillus licheniformi (Le Campion et al., 1999b). IMX-101 constituents provided as the sole nitrogen sources have also been shown to be degraded aerobically by microorganisms found in soils used in the previous section of this study. Very limited information has be conducted on the ability of plants to aid in the removal of IMX-101 constituents, however NQ has been shown to be translocate to the leaves of both tall fescue (Festuca arundinacea) and soybean (Glycine max) (Heitholt et al., 1990). It is therefore expected that some level of biological removal of IMX-101 compounds may occur in soils. 
The goal of this study was to evaluate the fate of IMX-101 in the environment. A simulated rainfall study was used to determine the rate IMX-101 constituents dissolve from an IMX-101 fragment. Measurement of DNAN and NTO adsorption onto soils was observed. Additionally, this study assessed the ability of grasses to tolerate and grow in IMX-101 contaminated soil. Removal of IMX-101 from soils and uptake by grasses was observed under varying concentrations of IMX-101 contamination. We also assessed if the addition of IMX-101 degrading bacterial increase the rate of IMX-101 removal from soils.

\subsection{Materials and Methods}

\subsubsection{Adsorption/Desorption Experiments}

The adsorption of IMX-101 to different materials was tested on a set of three different soils. These soils are described in Table 3-1. Each soil was allowed to dry for a week and then sieved through a $2 \mathrm{~mm}$ sieve. Soil portions of one gram were added to glass test tubes capped with PTFE caps and sterilized ( $1 \mathrm{~h}, 121$ ${ }^{\circ} \mathrm{C}$ ) three separate times. A volume of $10 \mathrm{~mL}$ IMX-101 solution resulting in maximum potential soil concentrations of $10,100,500,750$ and $1000 \mathrm{mg} \cdot \mathrm{kg}^{-1}$ was added to target concentrations of $1,10,50,75$, and $100 \mathrm{mg} \cdot \mathrm{L}^{-1}$ to each type of soil in duplicate. Samples were destructively sampled at $0,3,6,12$, and $24 \mathrm{~h}$ from the start of the experiment. Test tubes were laid horizontally in a dark shaker table set to 200 RPM and maintained at room temperature $\left(30^{\circ} \mathrm{C}\right)$. Samples were then removed from the shaker table, centrifuged at 4000 RPM for $20 \mathrm{~min}$ and the supernatant was removed and filtered through a $0.45 \mu \mathrm{m}$

filter for HPLC analysis. Desorption tests were conducted on the 24 hour $100 \mathrm{mg} \cdot \mathrm{L}^{-1}$ samples by adding $10 \mathrm{~mL}$ of MilliQ water (Barnstead NanoPure, ThermoScientific, Waltham, MA) and shaking for $24 \mathrm{~h}$. Supernatant was collected as previously described and retained for HPLC analysis. Abiotic controls, which included soilless tubes were also prepared with $100 \mathrm{mg} \cdot \mathrm{L}^{-1} \mathrm{IMX}-101$ in duplicate and sampled after 24 hours. Soil fractions were determined from sieve testing. All soil was found to pass a No 10 (2 mm) sieve. Soils passing a No. $200(0.074 \mathrm{~mm})$ sieve were considered clay/silt, the remainder was considered sand. $\mathrm{P}_{2} \mathrm{O}_{5}, \mathrm{~K}_{2} \mathrm{O}, \mathrm{CEC}$ and $\mathrm{pH}$ were analyzed by WVU soil extension services. Organic content was determined by weight loss via ignition at $360^{\circ} \mathrm{C}$. 


\begin{tabular}{|c|c|c|c|}
\hline & Sand & Clay & $\begin{array}{l}\text { Towers } \\
\text { Soil }\end{array}$ \\
\hline Organic content & - & - & $1 \%$ \\
\hline Sand $(\%)$ & 99.97 & 47 & 79 \\
\hline Clay + Silt (\%) & 0.03 & 53 & 21 \\
\hline CEC (MEQ $\left.\cdot 100^{-1}\right)$ & - & - & 14 \\
\hline $\mathrm{P}_{2} \mathrm{O}_{5}\left(\mathrm{mg} \cdot \mathrm{kg}^{-1}\right)$ & - & - & 60 \\
\hline $\mathrm{K}_{2} \mathrm{O}\left(\mathrm{mg} \cdot \mathrm{kg}^{-1}\right)$ & - & - & 398 \\
\hline $\mathrm{pH}$ & - & - & 6.6 \\
\hline
\end{tabular}

\subsubsection{IMX-101 particle dissolution experiments}

Gravity fed deionized (DI) water was dropped onto a small fragment $(\sim 150 \mathrm{mg}, \sim 0.85 \mathrm{~cm}$ x $0.8 \mathrm{~cm})$ of IMX-101 at an average flow rate of $0.20 \mathrm{mg} \cdot \mathrm{mL}^{-1}$. The IMX-101 particle was suspended on a screen mesh above a large flask to collect the dissolved water. Periodically, the remaining fragment was allowed to dry and its weight measured and recorded. The fragment was weighed several times over a period of 24 days. Images of the IMX-101 fragment on days $0,4,10,20$ and 22 were taken with a camera and on day 22 with an Eclipse E600 (Nikon, Tokyo, Japan).

\subsubsection{Phytoremediation studies}

The organic soil used in adsorption experiments was used for phytoremediation studies but was mixed with multi-purpose sand in a 1:1 ratio. Aqueous IMX-101 was added to the soil mixture to target concentrations of $0,1,5,10,15,25$, and $50 \mathrm{mg} \cdot \mathrm{kg}^{-1}$ using a cement mixer. Soils were placed in the dark to dry for 50 days. Following mixing, clumping of soils was observed and the soil was loosened with mortar and pestle. Soils were passed through a $2 \mathrm{~mm}$ mesh sieve before being added to 2.5 " X10" DeepPots $^{\mathrm{TM}}$ (Stuewe \& Sons, Tangent, Oregon). An enrichment of microorganisms (enriched prior to bioremediation studies) from activated sludge from a wastewater treatment plant (Star City, WV) was grown in minimal salts media described in Section 2.2 with IMX-101 and carbon and nitrogen provided as well. The treatments are described in Table 3-2. The enriched culture was grown for a period of 30 days and mixed into the top $4 \mathrm{~cm}$ of soil of assigned containers. A seed mixture ( 70 seeds) of $21 \%$ Andropogon gerardii (big bluestem), 21\% Sorghastrum nutans (Indiangrass), 58\% Panicum 
vigratum(Switchgrass) was added to the tops of containers and then covered with soil. Seeds were purchased from Ernst Conservations Seeds Inc. (Meadville, PA). Soils with high and low concentrations ( 1 and $50 \mathrm{mg} \cdot \mathrm{kg}^{-1}$ ) were prepared without seeds or additions of microorganisms to assess degradation by the natural microorganisms present. Grasses were grown in a plastic greenhouse (at $39.63^{\circ} \mathrm{N}, 79.95^{\circ} \mathrm{W}$ ) and were planted in early August and ran until late February. Temperatures in the greenhouse over the course of the experiment averaged a high of $90^{\circ} \mathrm{F}\left(+/-13^{\circ} \mathrm{F}\right)$ and a low $63^{\circ} \mathrm{F}\left(+/-9{ }^{\circ} \mathrm{F}\right)$. Average daily solar radation was measured to be $147 \mathrm{~W} \cdot \mathrm{m}^{-2} \cdot \mathrm{s}^{-1}$. Insufficient stand development was observed following 75 days and pots were reseeded with approximately 40 seeds with the previous seed mixture. Only enough water was fed to maintain moisture levels during germination to prevent water from leaching out of the bottom of the container. Leaching from containers was not accounted for, but was not expected based on amount of water added. After stand development was observed, water was added from below to minimize transport of IMX-101. Pots were destructively sampled at the start of the experiment, the day of re-germination, then 70, 120, and 150 days following re-germination. Pot locations were randomized to minimize environmental effects due to spatial differences within the greenhouse.

\section{Table 3-2- List of treatments}

\begin{tabular}{|l|l|l|l|}
\hline Sampling time & $\begin{array}{l}\text { Concentration of IMX-101 }(\mathrm{mg} \cdot \mathrm{kg}-1 \\
)\end{array}$ & Plants added & Culture added \\
\hline $0,70,195,225$ days & $1,5,10,15,25,50$ & Yes & Yes \\
\cline { 2 - 4 } & 1 and 50 & No & No \\
\hline 0 and 225 days & 0 & Yes & No \\
\hline $0,70,195,225$ days & 0 & & \\
\hline
\end{tabular}

During destructive sampling, samples were transported to the lab and soils were removed from planters and placed onto a clean sheet of newspaper. Roots and shoots were carefully separated from soil and rinsed thoroughly with DI water to remove excess soil and then dried overnight. Roots and shoots were separated, then measured and weighed. The roots and shoots were then placed into plastic sandwich bags and stored at $-80{ }^{\circ} \mathrm{C}$ until extraction and analysis. The top $2 \mathrm{~cm}$ of soil from each planter was discarded. The remaining soil was mixed to promote homogeneity and stored similarly at $-20{ }^{\circ} \mathrm{C}$ until extraction and analysis. 


\subsubsection{Analytical methods}

Soils were analyzed for explosive compounds following a modified version of the EPA 8330 methods. NTO and NQ were extracted from soils by adding $2 \mathrm{~g}$ of dry soil to $20 \mathrm{~mL}$ glass vials and adding $4 \mathrm{~mL}$ of DI water. Samples were then shaken in the dark at 150 RPM for 18 hours. Samples were allowed to settle for 30 minutes and then syringe filtered $(0.45 \mu \mathrm{m}$ nylon filter, FisherBrand, Waltham, MA) into amber vials for LC analysis. DNAN was extracted by adding $2 \mathrm{~g}$ of dry soil to and adding $4 \mathrm{~mL}$ acetonitrile. Following a 20 minute settling $3 \mathrm{ml}$ of supernatant was added to test tubes with $3 \mathrm{~mL} \mathrm{CaCl}_{2}$ swirled to mix and re-settled for $30 \mathrm{~min}$. Supernatant was then syringe filtered into amber $2 \mathrm{~mL}$ vials for HPLC analysis. Root and shoot samples were rinsed with DI water to remove any soil particles and allowed to dry. Samples were frozen at $-80{ }^{\circ} \mathrm{C}$ and then ground with a mortar and pestle to a fine powder. Ground material was dried, weighed and added to 4-12 mL methanol (depending on the amount needed to completely cover the ground material). Samples were mixed for 18 hours in the dark and allowed to settle. Solvent was extracted and re-filtered for LC analysis.

Specific conditions for HPLC and UPLC-MS/MS analysis have been previously described in section 2.2.4. HPLC analysis was run on a Shimzadzu HPLC-PDA system (SCL-10A system controller, LC-6AD pumps, SIL-10AP auto sampler, and SPD-10AV UV/Vis detector, Columbia, MD) and was used for DNAN and NTO analysis with limit of detection of $1 \mathrm{mg} \cdot \mathrm{L}^{-1}$ for both compounds. Acetonitrile was purchased from EMD Millipore (Billerica, MA, 99.8\% purity), trifluoroacetic acid was purchased from Sigma-Aldrich (St. Louis, MO, HPLC grade) and water was purified by a Nanopure Infinity system (Barnstead, Dubuque, IA, 18 $\Omega$ ). A ThermoScientific Accela (UPLC-MS/MS) system attached to a quadrapole mass detector and orbitrap analyzer (QExactive, ThermoScientific, Waltham, MA) was used to detect NQ and NTO in samples with a detection limit of $0.5 \mathrm{mg} \cdot \mathrm{L}^{-1}$. The mass to charge ratios for NTO and NQ were 103.0248 and $129.0041 \mathrm{~m} / \mathrm{z}$, respectively. Methanol and water were LCMS grade while ammonium acetate was HPLC grade and were all purchased from Fisher Scientific (Waltham, MA). 
Plots were produced using SigmaPlot 11® (Systat Software Inc., San Jose, CA) software. Analysis of variance between treatments was conducted using the PROC GLM subroutine of SAS (v. 9.4; SAS, Chicago, IL). Least squared means were determined between groups and for mixed effects (alpha $=0.05)$ using post hoc student's t-test.

\subsection{Results}

\subsubsection{Dissolution Study}

A decrease in particle weight was seen over 24 days after approximately 7 liters of $\mathrm{H}_{2} \mathrm{O}$ was dropped onto the particle (Figure 3-1). Images taken of the particle during the dissolution experiments at 0,20 and 22

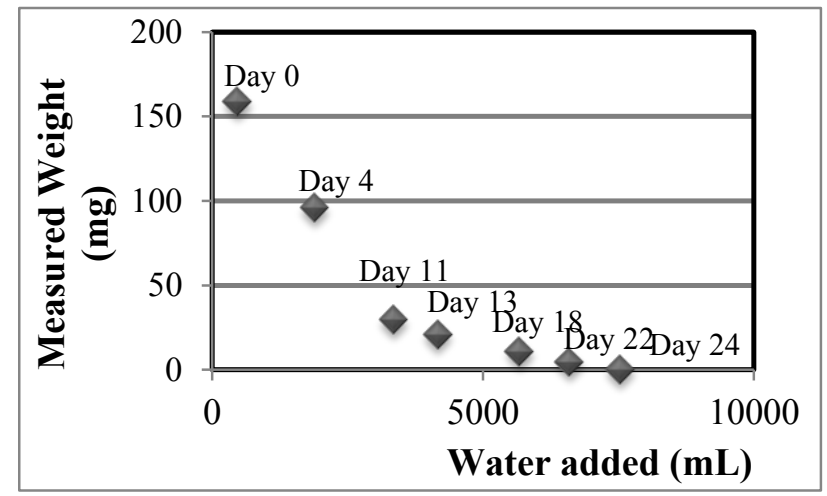

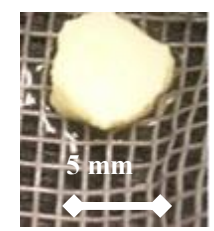

Day 0

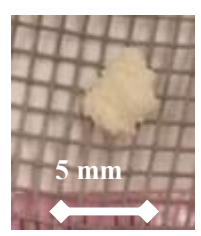

Day 20

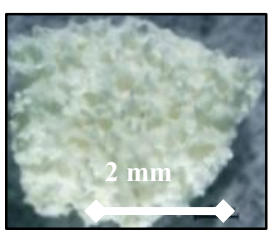

Day 22

Figure 3-2 - Dissolution of IMX-101 by simulated rainfall over time. A higher resolution in day 22 illustrates the effect dissolution had on the particle.

Figure 3-1 - IMX-101 dissolution with de-ionized water over 24 days.

days are shown in Figure 3-2. The particle was not rapidly dissolved by the simulated rainfall and required more than 8 liters to dissolve the compound to near complete dissolution, which would have represented a significant amount of rainfall. IMX-101 constituents where not seen to dissolve at the same rate observed in Figure 3-2. Water collected following contact with the particle was observed showed a yellow color during the first week of the study, which would correspond to NTO based on previously reported solubilites and chemical characteristics of the compound. 


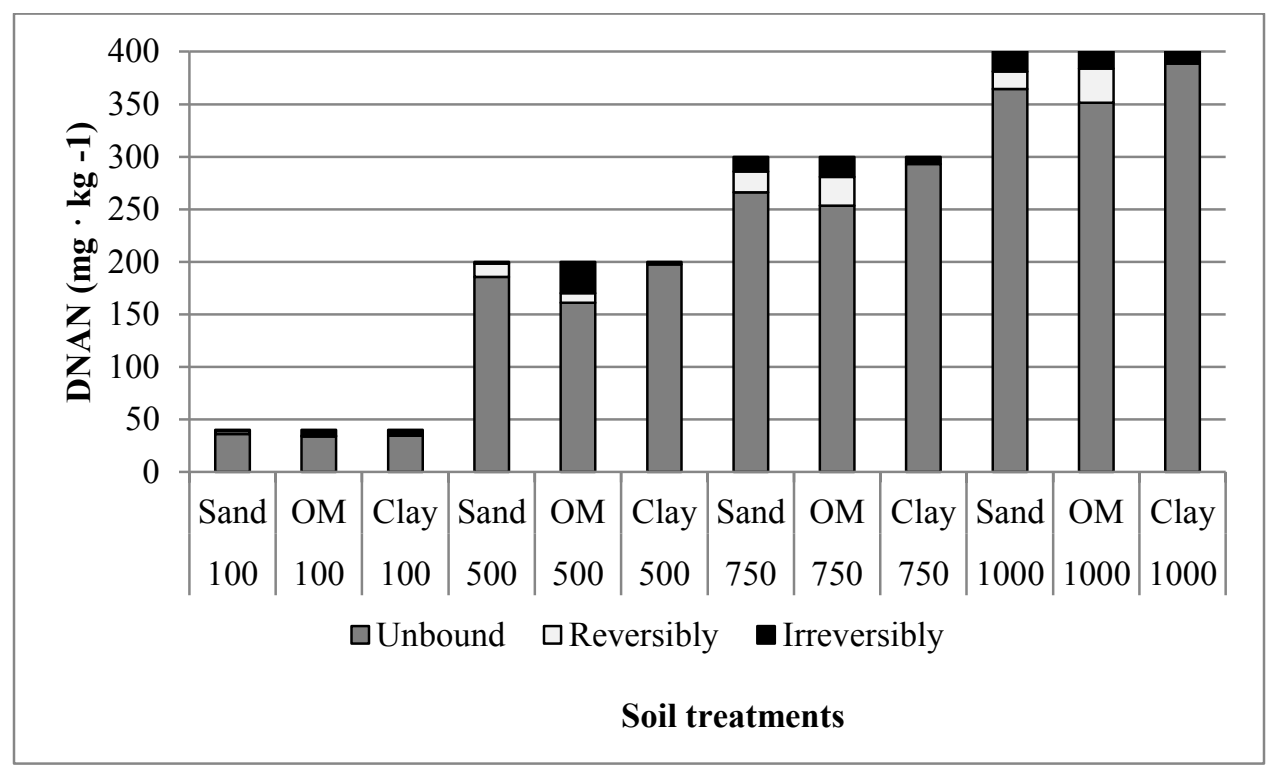

Figure 3-3 - Fractions of DNAN (ir)reversibly bound to sand, clay and organic soil $(n=2)$.

\subsection{2 - Adsorption}

Adsorption of IMX-101 (i.e., NTO and DNAN) onto various soils was observed over a 24 hour period.

No adsorption of NTO concentrations was observed in any of the treatments (data not shown). Adsorption of DNAN to the three soils tested is presented Figure 3-3. The amount of IMX-101 added and the estimated percentage of DNAN was used to determine the ratio of DNAN in the aqueous phase.

Approximately of $20 \%$ of total DNAN provided was adsorbed throughout in organic soil treatments and was only partially recovered following desorption, while $12 \%$ of DNAN was the maximum adsorption seen in sand treatments. A very small fraction was seen to adsorb to the clay soil. The no soil control for this treatment also observed adsorption DNAN but saw no desorption and cannot account for losses seen in the $400 \mathrm{mg} \cdot \mathrm{kg}^{-1}$ treatment. Although adsorption DNAN was observed in each soil, only a very small fraction of DNAN was irreversible adsorbed to any one soil.

\subsection{3 - Plant growth}

The addition of culture on normalized masses of roots and shoots was seen to be statistical significance at $1 \mathrm{mg} \cdot \mathrm{kg}^{-1}$ (Figure 3-5). It was also evident that with increasing IMX-101 concentrations root and shoot masses decreased on average (Figure 3-8). No effect on root length was seen by IMX-101 concentrations or the addition of culture, and root growth was likely limited by the depth of the container being used (Figure 3-4). While there was no observable effect of IMX-101 concentrations on shoot length, statistical 
differences were observed in culture additions at 1 and $10 \mathrm{mg} \cdot \mathrm{kg}^{-1}(\mathrm{P}<0.01)$. Growth in 25 and $50 \mathrm{mg} \cdot$ $\mathrm{kg}^{-1}$ treatments was seen to have reduce growth of grasses in comparison to growth at lower concentrations (Figure 3-8).

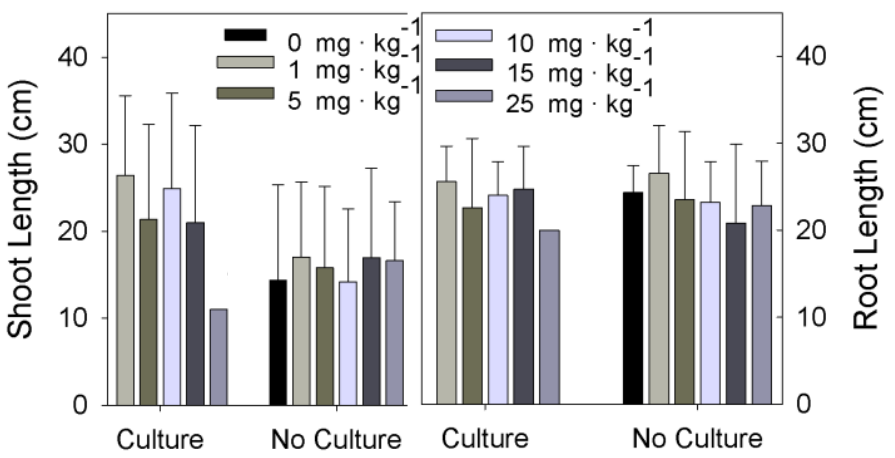

Figure 3-4 - Maximum shoot and root length for each pot. Error bars represent standard deviation. $25 \mathrm{mg} \cdot \mathbf{k g}^{-1}$ culture treatment $n=1$, otherwise $n>7$.

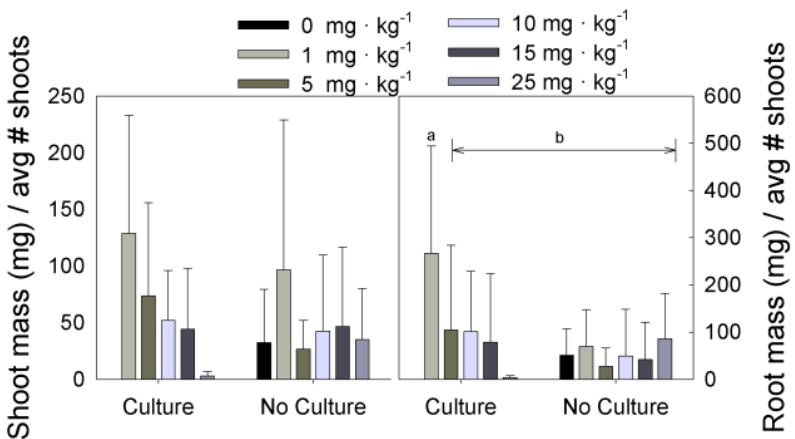

Figure 3-5 - Average root/shoot mass per shoot comparing culture vs. no culture added. Error bars represent standard deviation. The $25 \mathrm{mg} \cdot \mathrm{kg}^{-1}$ culture treatment $n=2$, otherwise $n>7$. 

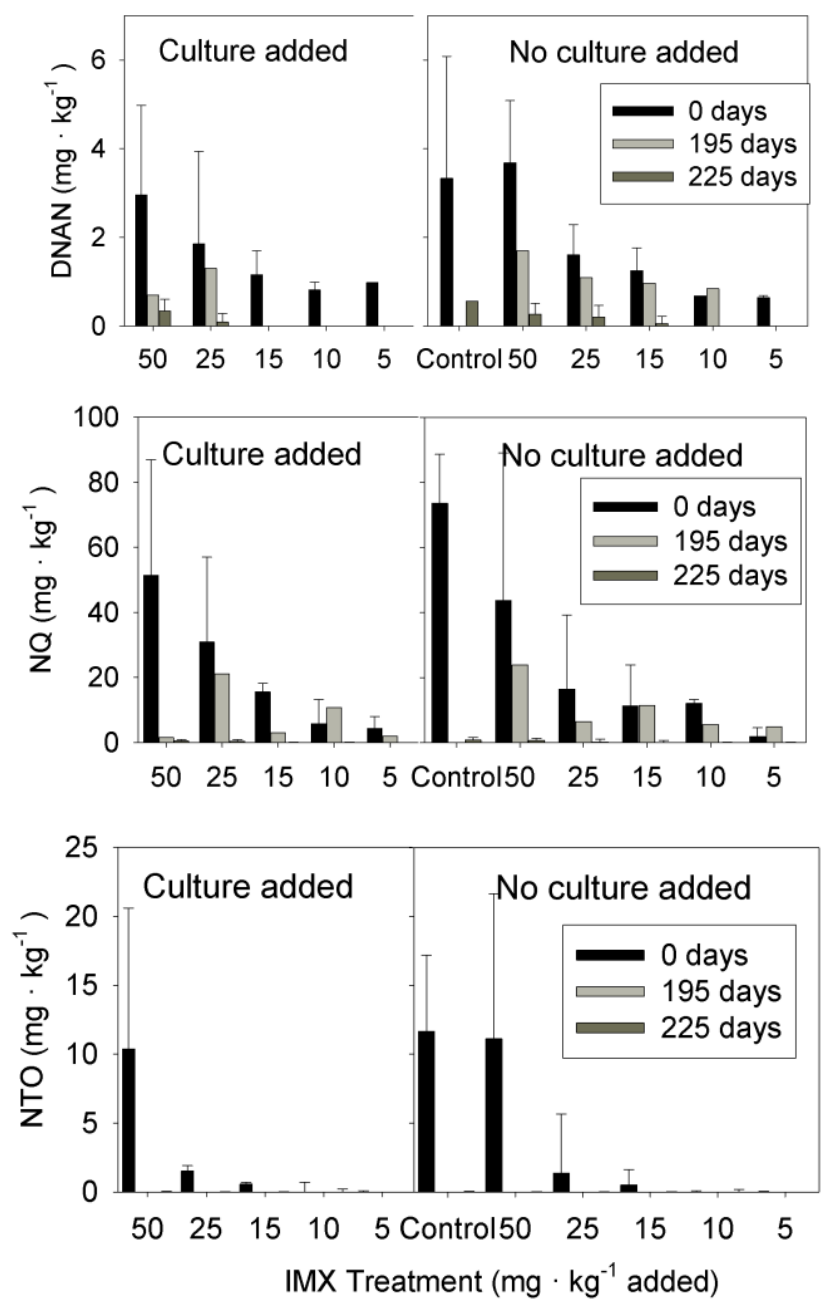

Figure 3-6 -Average and standard deviation of DNAN, NQ and NTO concentrations in soils with plants added over time after seeding. No plant control treatment soil was at $50 \mathrm{mg} \cdot \mathrm{kg}^{-1}$ and was not measured at 195 days. 


\begin{tabular}{|c|c|c|c|c|c|}
\hline & \multirow{2}{*}{$\begin{array}{c}\text { Targeted } \\
\text { Concentration } \\
\left(\mathrm{mg} \cdot \mathrm{L}^{-1}\right)\end{array}$} & \multicolumn{2}{|c|}{ DNAN } & \multicolumn{2}{|c|}{ NQ } \\
\hline & & Root & Shoot & Root & Shoot \\
\hline \multirow{2}{*}{$\begin{array}{l}\text { Culture } \\
\text { addition }\end{array}$} & 10 & 3 & 3 & 3 & $4(100 \%)$ \\
\hline & 15 & $2(50 \%)$ & 2 & 2 & No data \\
\hline \multirow{3}{*}{$\begin{array}{l}\text { No Culture } \\
\text { addition }\end{array}$} & 10 & $2(50 \%)$ & 2 & 1 & $2(100 \%)$ \\
\hline & 15 & 2 & 2 (100\%) & 2 & $2(50 \%)$ \\
\hline & 25 & $1(100 \%)$ & 1 & 2 (100\%) & 2 \\
\hline
\end{tabular}

\begin{tabular}{|c|c|c|}
\cline { 2 - 3 } \multicolumn{1}{c|}{ Legend } & DNAN & $\begin{array}{c}\text { NQ } \\
\mathrm{mg} \mathrm{NQ} / \mathrm{mg} \text { biomass }\end{array}$ \\
\hline & Absent & Absent \\
& Present & $.0001-.001$ \\
- & $.001-.01$ \\
- & $<0.01$ \\
\hline
\end{tabular}

Figure 3-7 - DNAN presence or absence $\left(>1 \mathrm{mg} \cdot \mathrm{kg}^{-1}\right)$ in the roots and shoots of various treatments. NQ concentration ranges in roots and shoots of treatments. Where the number of plants tested in each treatment are shown for each cell and the relative color of the cell indicates observed concentrations.

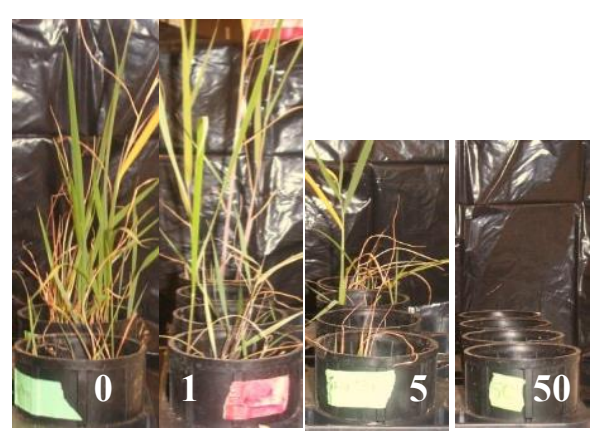

Figure 3-8 - Effect of IMX-101

concentrations $\left(\mathrm{mg} \cdot \mathrm{kg}^{-1}\right)$ on the growth of grasses after 195 days.

\subsection{4 - IMX-101 concentrations in soil/roots/shoot}

Based on adsorption studies NTO was not expected to be retained on soils, which was observed in the rapid decreases in soil concentrations. Control treatments, where neither plants nor culture were added, saw significant reduction of both DNAN and NQ by day 195. Control soils were not sterilized prior to the initiation of the study suggesting that significant degradation of IMX-101 may occur in soils due solely to native microbial populations or abiotic oxidation or reduction reactions. At lower concentrations of IMX101, removal of DNAN in soil appears to increase with the addition of microorganisms. Further all 
treatments observed removal to near the limit of detection by 225 days. NQ removal rates closely follow those of DNAN, and NTO is nearly non-detectable after 225 days.

NQ and DNAN concentrations in roots and shoots were measured and are presented in a heat map in Figure 3-7. NTO was not detected in any roots or shoots and was omitted from the figure. NQ was detected primarily in the shoots of grasses rather than the roots. Lower levels of NQ were present in roots, but were below the quantifiable detection limit and would be present for NQ to pass to the leaves/shoots.

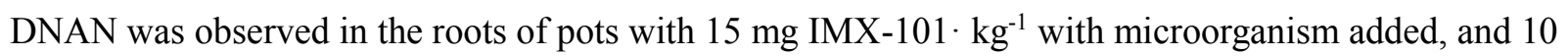

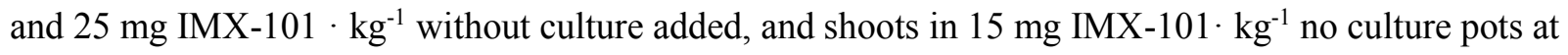
low concentrations (i.e., $\left.<1 \mathrm{mg} \cdot \mathrm{L}^{-1}\right)$.

\subsection{Discussion}

During military testing and training exercises deposition of residual explosives on surface soils from UXO (Jenkins, 2001) and low-order detonations of explosives (Pennington, 2008) occurs. Fate and transport of compounds in these low order detonations are generally dependent on their physical and chemical properties and relate to the various attenuation processes (Pennington and Brannon, 2002) (Pennington, 2002). The most common attenuation mechanisms of explosive residues on ranges include dissolution, adsorption, biological transformation, and natural degradation (Brannon and Myers, 1997). As shown in Figure 3-9, the attenuation mechanisms studied in this work include dissolution, adsorption, uptake by plants (grasses), and biological and abiotic degradation.

Dissolution of the IMX-101 particle was conducted to illustrate possible releases into the environment from UXO and low-order detonations during rainfall. In this study rapid dissolution was predominantly associated with NQ and NTO compounds based on laboratory observations and previously reported values (Haag et al., 1990; Becker, 1995) on compound solubility. DNAN is not as soluble as the two other compounds in the formulation and DNAN would likely be the primary constituent of the particle during the later stages of dissolution (Figure 3-2). Rates of dissolution reported herein however would 
likely be lower than those seen in the field, due to ions presence in rainwater (compared to DI water used in this study). Dissolution of IMX-101 constituents on military ranges would be seen with significant rainfall; however DNAN may exist on the surface for extended periods in arid environments.

Photodegradation, which has been shown to occur with NQ and DNAN (Rao et al., 2013; Burrows et al., 1988)), has the potential to occur with incomplete dissolution of IMX-101 on soil surfaces. While compounds on the soil surface in arid environments would be more susceptible to photodegradation, wetter environments would likely transport compound into the subsurface where light can penetrate. Further, photodegradation of these compounds has been previously studied and for these reasons was not evaluated in this study.

Adsorption of IMX-101 compounds were measured to observe if retention on soils will occur following dissolution into the soil column. DNAN removal from aqueous solution suggests that soils do have the capacity to adsorb some portion of the compound. Conversely, attenuation of NTO by soil is less likely to be seen. Although no assessment of NQ adsorption was conducted herein, Gosch (2012) and Haag et al. (1990) showed limited adsorption of NQ on soils and sediments would be unexpected. The movement of DNAN would therefore be in part retained on soils following dissolution, with the remaining fraction moving with soil pore water similar to NTO and NQ. Unfortunately, collection of the leachate was not measured in this study. However, significant efforts were made to prevent the occurrence of the leachate by adding minimal water during germination and bottom watering following shoot emergence.

A detrimental effect on germination of Andropogon gerardii (big bluestem), Sorghastrum nutans (Indiangrass), Panicum vigratum by IMX-101 constituents was observed at higher concentrations (25 and $\left.50 \mathrm{mg} \cdot \mathrm{kg}^{-1} \mathrm{IMX}\right)$. The addition of IMX-101 degrading microbial culture saw no effect on germination but were seen to increase root mass and shoot length. This growth may have been promoted by either or a combination of larger initial microbial populations, interactions of bacteria with the rhizosphere, or by increased microbial degradation of IMX-101 compounds. Culture addition was also seen to increase the removal of DNAN in soils, but limited to no effect was seen on the removal rate of NQ. In batch 
biodegradation studies with IMX-101 provided, microorganisms isolated from soil were observed to degrade DNAN prior to NQ and NTO as well as a delay in degradation was seen to occur for NQ (Section 2). These results suggest that organisms in culture added to soils were more prone to utilization of DNAN than NQ.

Reduction of IMX-101 concentrations in soils to near limit of detection was seen in nearly all treatments over the 225 day period. Experimental controls where seeds were not added observed reductions in concentration very similar to those seen in seeded pots, suggesting that removal by grasses is not likely to account for a significant fraction of compound removal. Further, studies presented in Chapter 2 showed biodegradation of IMX-101 compounds by organisms isolated from the soil used in the growth experiments. Other authors have also shown biodegradation of NQ and DNAN in soil microcosms (Perreault et al., (2012a\&b). This suggests that the reduction of IMX-101 compounds is primarily a result of abiotic losses, degradation by microorganisms present in the soil or photodegradation.

Interestingly, NTO removal was seen to occur with the most rapid rate, contrary to results presented above and may suggest that an alternative mechanism is responsible for losses.

It is not expected that reduced concentrations of IMX-101 in these soils are from phytoremediation mechanisms, the detection of NQ and DNAN in root and shoot material suggests that phytoaccumulation of these compounds may be possible. NQ accumulation was seen to occur primarily in the shoot (includes leaves) portions, which was also seen by Heitholt et al. (1990)

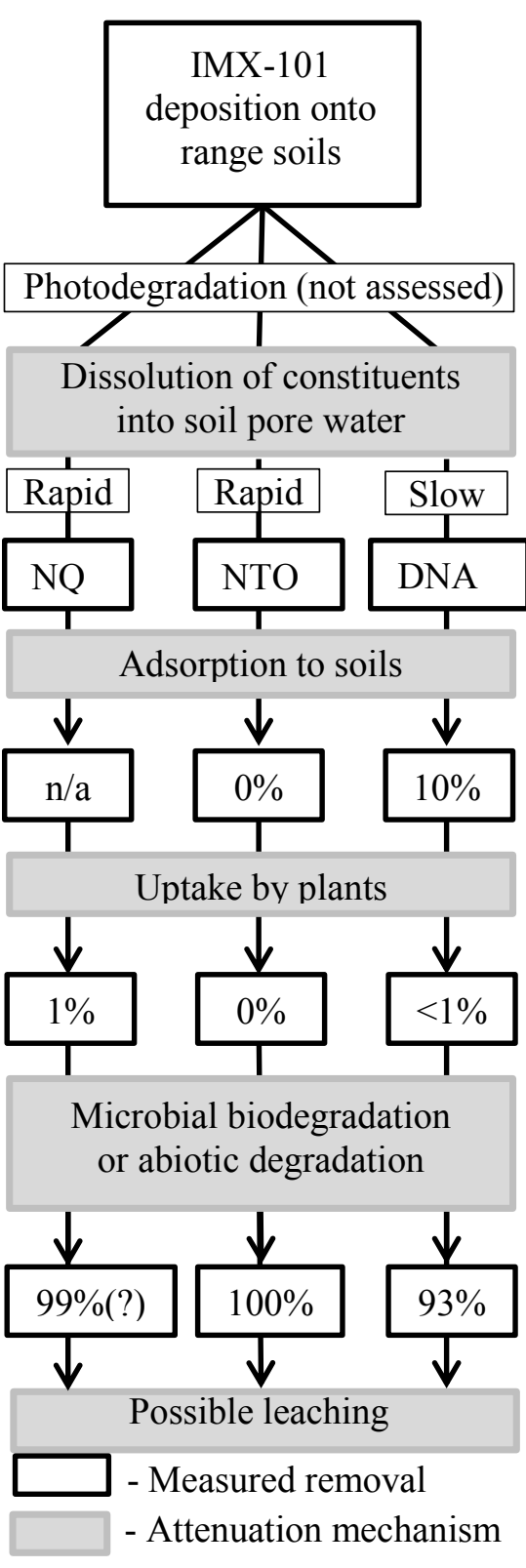

Figure 3-9 - Estimated percent IMX101 attenuated by different mechanisms examined in this study. 
where NQ accumulation primarily in the leaves of Tall fescue (Festuca arundinacea) and soybean (Glycine max). However, phytoaccumulation of NQ and DNAN would not likely account for any significant removal of these munitions from testing and training range soils due to biological degradation by microorganisms.

Though these results do not show significant evidence of phytoremediation of IMX-101 compounds by the grass mixture, a semi-rapid removal of these compounds by natural processes was observed. This study has shown that these compounds do have an effect on the germination of the grasses. The addition of culture to the surface of soil was shown to increase growth and removal of IMX-101, but the necessity of the addition may be inadvisable as removal seen in treatments where culture and grass seed was added were nearly equivalent to those seen in controls. Data presented herein may help defense agencies develop strategies for treatment of ranges where IMX-101 is being used. 


\section{Conclusions}

Culture from both natural and engineered systems were also shown capable of aerobic and anaerobic degradation of IMX-101. Rapid acclimation ( $<1$ week) and biodegradation and utilization of DNAN NQ, and NTO as a sole nitrogen source under aerobic conditions has also been observed. Characterization of inhibited growth kinetics on DNAN and NQ was evaluated using the Monod model $\left(\mu_{\max }=0.1050 \mathrm{~h}^{-1}\right.$ and $\mathrm{K}_{\mathrm{s}}=9.975 \mathrm{mg} \cdot \mathrm{L}^{-1}$ ) and was observed similar to reported phenol degradation. It may be valuable to assess kinetics for individual compounds that make up IMX-101. Additionally, there is a need to characterize aerobic degradation of NTO in absence of DNAN and NTO. Further, future studies should determine end products of IMX-101 when used as a sole source of nitrogen to confirm degradation pathways. IMX-101 fate and transport on military testing and training ranges is likely to move from the surface into the soil. Retention of DNAN the soil is like to occur to some degree, while NTO and NQ adsorption to soil is not expected. However, these deposition of these compounds on soils in arid climates may result in reduced germination rates of grasses should concentrations exceed $15 \mathrm{mg} \cdot \mathrm{kg}^{-1}$. The effect of grasses on the removal of IMX-101 constituents on soils was seen to be insignificant in comparison to removal by biological degradation by microorganisms or abiotic losses. These data has provided further characterization of the fate and transport of IMX-101 compounds in the environment and will aid in the development of remediation strategies. 


\section{References}

Arnett, C. M., Rodriguez, G., and Maloney, S. W. (2009). "Analysis of Bacterial Community Diversity in Anaerobic Fluidized Bed Bioreactors Treating 2,4-Dinitroanisole (DNAN) and $n$-Methyl-4-nitroaniline (MNA) Using 16S rRNA Gene Clone Libraries." Microbes and Environments, 24(1), 72-75.

Becker, N. M. (1995). "Fate of selected high explosives in the environment: A literature review." Rep. No. LA-UR-95-1018, Los Alamos National Laboratory Report.

Best, E. P., Smith, T., Hagen, F. L., Dawson, J. O., and Torrey, A. J. (2008). "Capacities of Candidate Herbaceous Plants for Phytoremediation of Soil-based TNT and RDX on Ranges." Rep. No. No. ERDCTR-08-8, Engineer Research and Development Center, Vicksburg, MS.

Boddu, V., Abburi, K., Fredricksen, A., Maloney, S., and Damavarapu, R. (2009). "Equilibrium and column adsorption studies of 2,4-dinitroanisole (DNAN) on surface modified granular activated carbons." Environmental Technology, 30(2), 173-181.

Boddu, V., Abburi, K., Maloney, S., and Damavarapu, R. (2008). "Thermophysical properties of an insensitive munitions compound, 2,4-dinitroanisole." Journal of Chemical and Engineering Data, 53(5), $1120-1125$.

Brannon, J. M., and Myers, T. E. (1997). "Review of Fate and Transport Processes of Explosives." Rep. No. No. WES/TR/IRRP-97-2, Army Engineer Waterways Experiment Station, Vicksburg, MS.

Burrows, W. D., Schmidt, M. O., Chyrek, R. H., and Noss, C. I. (1988). "Photochemistry of Aqueous Nitroguanidine." Rep. No. No. USABRDL-TR-8808, Army Biomedical Research and Development Lab, Fort Detrick, MD.

Crocker, F. H., Indest, K. J., and Fredrickson, H. L. (2006). "Biodegradation of the cyclic nitramine explosives RDX, HMX, and CL-20." Applied Microbiology and Biotechnology, 73(2), 274-290.

Davies, P. J., and Provatas, A. (2006). "Characterisation of 2, 4-dinitroanisole: An ingredient for use in low sensitivity melt cast formulations." Rep. No. No. DSTO-TR-1904., Defence Science and Technology Organisation Weapons Systems Division, Edinburgh, Australia.

DeFisher, S., Pfau, D., and Dyka, C. (2010). "Insensitive Munitions Modeling Improvement Efforts ." Army Armament Research Development and Engineering Center Picatinny Arsenal, NJ.

Gosch, D. (2012). "Determining fate and transport parameters for nitroglycerine, 2,4-dinitrotoluene, 2,6dinitrotoluene and nitroguanidine in soils".

Haag, W., Spanggord, R., Mill, T., Podoll, R., Chou, T., TSE, D., and Harper, J. (1990). "Aquatic Environmental Fate of Nitroguanidine." Environmental Toxicology and Chemistry, 9(11), 1359-1367.

Haldane, J. B. S. (1965). "Enzymes." M.I.T. Press, Cambridge, MA, 85. 
Haley, M. V., Kuperman, R. G., and Checkai, R. T. (2009). "Aquatic Toxicity of 3-Nitro-1, 2, 4-Triazol5-One." Rep. No. ECBC-TR-726, Edgewood Chemical Biological Center Aberdeen Proving Ground MD Research and Technology, .

Heitholt, J. J., Hodgson, R. H., and Tworkoski, T. J. (1990). "Toxicity and uptake of nitroguanidine in plants." Bull.Environ.Contam.Toxicol., 44(5), 751-758.

Hurst, C. J., and Crawford, R. L. (2007). "Manual of environmental microbiology." ASM Press, Ed. 3.

Jenkins, T. F., Pennington, J. C., Ranney, T. A., Berry, T. E. J., Miyares, P. H., Walsh, M. E., Hewitt, A. D., Perron, N. M., Parker, L. V., Hayes, C. A., and and Wahlgren, E. G. (2001). "Characterization of Explosives Contamination at Military Firing Ranges." Rep. No. ERDC/CRREL TR-01-5, US Army Engineer Research and Development Center, Cold Regions Research and Engineering Laboratory, Hanover, New Hampshire.

Kaplan, D. L., Cornell, J. H., and Kaplan, A. M. (1982). "Decomposition of nitroguanidine." Environmental Science and Technology, 16(8), 488-492.

Kennedy, A. J., Lounds, C. D., Melby, N. L., Laird, J. G., Winstead, B., Brasfield, S. M., and Johnson, M. S. (2013). "Development of Environmental Health Criteria for Insensitive Munitions: Aquatic Ecotoxicological Exposures Using 2,4-Dinitroanisole." Rep. No. ERDC/EL TR-13-2, U.S. Army Engineer Research and Development Center, Vicksburg, MS.

Kumaran, P., and Paruchuri, Y. L. (1997). "Kinetics of phenol biotransformation." Water Res., 31(1), 1122.

Le Campion, L., and Ouazzani, J. (1999). "Synthesis of 5-Amino-1,2,4-Triazole-3-One Through the Nitroreduction of 5-Nitro-1,2,4-Triazole-3-One. Comparison Between Chemical and Microbiological Catalysis." Biocatalysis Biotransformation, 17(1), 37-44.

Le Campion, L., Vandais, A., and Ouazzani, J. (1999). "Microbial remediation of NTO in aqueous industrial wastes." FEMS Microbiology Letters, 176(1), 197-203.

Le Campion, L., Giannotti, C., and Ouazzani, J. (1999). "Photocatalytic degradation of 5-Nitro-1,2,4Triazol-3-one NTO in aqueous suspention of TiO 2. Comparison with fenton oxidation." Chemosphere, 38(7), 1561-1570.

Lewis, T. A., Newcombe, D. A., and Crawford, R. L. (2004). "Bioremediation of soils contaminated with explosives." Journal of Environmental Management, 70(4), 291-307.

Olivares, C., Liang, J., Abrell, L., Sierra-Alvarez, R., and Field, J. A. (2013). "Pathways of reductive 2,4dinitroanisole (DNAN) biotransformation in sludge." Biotechnology and Bioengineering, 110(6), 15951604.

Pennington, J. C., Jenkins, T. F., Brannon, J. M., Lynch, J., Ranney, T. A., Berry, T. E. J., Hayes, C. A., Miyares, P. H., Walsh, M. E., Hewitt, A. D., Perron, N., Delfino, J. J., and . (2001). "Distribution and fate of energetics on DoD test and training ranges: interim report 1." Rep. No. ERDC TR-01-13, U.S. Army Engineer Research and Development Center, . 
Pennington, J. C., Jenkins, T. F., Thiboutot, S., Ampleman, G., Clausen, J., Hewitt, A. D., Lewis, J., Walsh, M. R., Walsh, M. E., Ranney, T. A., Silverblatt, B., Marois, A., Gagnon, A., Brousseau, P., Zufelt, J. E., Poe, K., Bouchard, M., Martel, R., Walker, D. D., Ramsey, C. A., Hayes, C. A., Yost, S. L., Bjella, K. L., Trepanier, L., Berry, T. E. J., Lambert, D. J., Dubé, P., and Perron, N. M. (2005). "Distribution and fate of energetics on DoD test and training ranges: interim report 5." Rep. No. ERDC TR-05-2, U.S. Army Engineer Research and Development Center, Vicksburg, MS,.

Pennington, J. C., and Brannon, J. M. (2002). "Environmental fate of explosives." Thermochimica Acta, 384(1-2), 163-172.

Perreault, N. N., Halasz, A., Manno, D., Thiboutot, S., Ampleman, G., and Hawari, J. (2012). "Aerobic mineralization of nitroguanidine by Variovorax strain $\mathrm{VCl}$ isolated from soil." Environmental Science and Technology, 46(11), 6035.

Perreault, N. N., Manno, D., Halasz, A., Thiboutot, S., Ampleman, G., and Hawari, J. (2012). "Aerobic biotransformation of 2,4-dinitroanisole in soil and soil Bacillus sp." Biodegradation, 23(2), 287-295.

Peterson, M. M., Horst, G. L., Shea, P. J., and Comfort, S. D. (1998). "Germination and seedling development of switchgrass and smooth bromegrass exposed to 2,4,6-trinitrotoluene." Environmental Pollution, 99(1), 53-59.

Picatinny PA. (2010). "Army approves safer explosive to replace TNT." http://www.army.mil/article/43553/ (6/03, 2013).

Pichtel, J. (2012). "Distribution and Fate of Military Explosives and Propellants in Soil: A Review." Applied and Environmental Soil Science, .

Platten III, W. E., Bailey, D., Suidan, M. T., and Maloney, S. W. (2010). "Biological transformation pathways of 2,4-dinitro anisole and N-methyl paranitro aniline in anaerobic fluidized-bed bioreactors." Chemosphere, 81(9), 1131-1136.

Rao, B., Wang, W., Cai, Q., Anderson, T., and Gu, B. (2013). "Photochemical transformation of the insensitive munitions compound 2,4-dinitroanisole." Science of the Total Environment, 443(0), 692-699.

Saad, R., Radovic-Hrapovic, Z., Ahvazi, B., Thiboutot, S., Ampleman, G., and Hawari, J. (2012). "Sorption of 2,4-dinitroanisole (DNAN) on lignin." Journal of Environmental Sciences, 24(5), 808-813.

Samuels, P. (September, 2010). "Email communication: Material Data Sheet: IMX-101." J. Weidhaas, .

Schalie, H. W. (1985). "The Toxicity of Nitroguanidine and Photolyzed Nitroguandine to Freshwater Aquatic Organisms." Rep. No. USAMBRDL-TR-8404, Army Medical Bioengineering Research and Development Lab, Fort Detrick, MD.

United States. (1989). "Military explosives." Rep. No. TM 9-1300-214, Department of the Army, Washington, D.C. Headquarters, Deptartment of the Army.

Walsh, M. R., Walsh, M. E., Taylor, S., Ramsey, C. A., Ringelberg, D. B., Zufelt, J. E., Thiboutot, S., Ampleman, G., and Diaz, E. (2013). "Characterization of PAX-21 Insensitive Munition Detonation Residues." Propellants, Explosives, Pyrotechnics, 38(3), 399. 
Young, D. M., Unkefer, P. J., and Ogden, K. L. (1997). "Biotransformation of hexahydro-1,3,5-trinitro1,3,5-triazine (RDX) by a prospective consortium and its most effective isolate Serratia marcescens." Biotechnology and Bioengineering, 53(5), 515-522. 